\title{
A Novel, Noninvasive, Predictive Epilepsy Biomarker with Clinical Potential
}

\author{
ManKin Choy, ${ }^{1,2 \star}$ Celine M. Dubé, ${ }^{2 \star}$ Katelin Patterson, ${ }^{2 \star ~}$ (1)Samuel R. Barnes, ${ }^{5}$ Pamela Maras, ${ }^{2}$ Arlin B. Blood, ${ }^{6}$ \\ Anton N. Hasso, ${ }^{3}$ Andre Obenaus, ${ }^{6}$ and Tallie Z. Baram ${ }^{1,2,4}$ \\ ${ }^{1}$ Department of Pediatrics, ${ }^{2}$ Department of Anatomy/Neurobiology, ${ }^{3}$ Department of Radiological Sciences, and ${ }^{4}$ Department of Neurology, University of \\ California-Irvine, Irvine, California 92697, and ${ }^{5}$ Department of Radiation Medicine and ${ }^{6}$ Department of Pediatrics, Loma Linda University School of \\ Medicine, Loma Linda, California 92350
}

A significant proportion of temporal lobe epilepsy (TLE), a common, intractable brain disorder, arises in children with febrile status epilepticus (FSE). Preventative therapy development is hampered by our inability to identify early the FSE individuals who will develop TLE. In a naturalistic rat model of FSE, we used high-magnetic-field MRI and long-term video EEG to seek clinically relevant noninvasive markers of epileptogenesis and found that reduced amygdala $\mathrm{T}_{2}$ relaxation times in high-magnetic-field MRI hours after FSE predicted experimental TLE. Reduced $\mathrm{T}_{2}$ values likely represented paramagnetic susceptibility effects derived from increased unsaturated venous hemoglobin, suggesting augmented oxygen utilization after FSE termination. Indeed, $\mathrm{T}_{2}$ correlated with energy-demanding intracellular translocation of the injury-sensor high-mobility group box 1 (HMGB1), a trigger of inflammatory cascades implicated in epileptogenesis. Use of deoxyhemoglobin-sensitive MRI sequences enabled visualization of the predictive changes on lower-field, clinically relevant scanners. This novel MRI signature delineates the onset and suggests mechanisms of epileptogenesis that follow experimental FSE.

Key words: biomarker; epilepsy; febrile seizures; inflammation; MRI; predictive

\section{Introduction}

Temporal lobe epilepsy (TLE) is a common, often treatmentresistant brain disorder (Cendes et al., 1993a; French et al., 1993). Childhood long febrile seizures, especially febrile status epilepticus (FSE; seizures >30 min), are significant risk factors for developing TLE: a history of FSE is found in 35-75\% of individuals with TLE (Annegers et al., 1987; Cendes et al., 1993b). Despite significant progress in understanding the mechanisms that underlie epileptogenesis, no preventative treatments are available. A major barrier to developing such therapies stems from the current inability to identify those who develop TLE after FSE until seizures emerge (Mathern et al., 1995; Kelley et al., 2009). Because the mean time to TLE onset after FSE is $8-12$ years (Mathern et al., 1995), a predictive marker should facilitate identification of candidates for future targeted interventions.

MRI is quantifiable and repeatable, enabling monitoring of disease onset and progression. MRI at low magnetic field has

Received Nov. 14, 2013; revised May 8, 2014; accepted May 13, 2014.

Author contributions: M.C., A.N.H., and T.Z.B. designed research;M.C.,C.M.D., K.P., and P.M. performed research; S.R.B., A.B.B., and A.N.O. contributed unpublished reagents/analytic tools; M.C., C.M.D., and K.P. analyzed data; M.C. and T.Z.B. wrote the paper.

This work was supported by the National Institutes of Health (Grants NS35439 and NS78279) and a predoctoral fellowship from the Epilepsy Foundation of America and the American Epilepsy Society. We thank A. Vezzani and T. Ravizza for their insight and support and Barbara Cartwright for excellent editorial assistance.

The authors declare no competing financial interests.

*M.C., C.M.D., and K.P. contributed equally to this work.

Correspondence should be addressed to Tallie Z. Baram, Department of Pediatrics and Anatomy/Neurobiology, Z0T 4475, University of California-Irvine, Irvine, CA 92697. E-mail: tallie@uci.edu.

DOI:10.1523/JNEUROSCI.4806-13.2014

Copyright $\odot 2014$ the authors $\quad 0270-6474 / 14 / 348672-13 \$ 15.00 / 0$ been used to study children with FSE and revealed generally unilateral increased $\mathrm{T}_{2}$ values within 2-5 d (VanLandingham et al., 1998; Scott et al., 2002; Lewis et al., 2014). Similar findings have been observed in immature rodent FSE models using similar time frames and relatively low-magnetic-field MRI systems (Dubé et al., 2004; Jansen et al., 2008). However, it remains unknown whether these changes predict epilepsy and the underlying neurobiological mechanisms are incompletely understood.

Here, we investigated MRI changes occurring within hours after FSE as potential predictive markers for TLE using a highresolution, high-field scanner. We used an established rat model of FSE induced by hyperthermia involving endogenous fever mediators (Dubé et al., 2005a, 2010) in rats at ages when limbic system development approximates that in children with FSE (Avishai-Eliner et al., 2002). Similar to children, 30-40\% of animals develop TLE, yet progression to epilepsy is relatively short (months), permitting rapid validation of identified markers (Roch et al., 2002; Gröhn and Pitkänen, 2007). In addition, whereas many factors likely contribute to TLE development after childhood FSE, we have established the causal role of rodent FSE in the subsequent epilepsy. We examined the neurobiological basis of the MRI changes seeking to identify epileptogenic mechanisms.

At early time points and using a very-high-field magnet (11.7 $\mathrm{T}$ ), novel and specific MRI signal changes were observed in limbic regions and these changes predicted TLE. The MRI signal changes involved local susceptibility effects derived from the paramagnetic nature of oxygen-poor, unsaturated hemoglobin. They appeared as reduced $\mathrm{T}_{2}$ on a high-field scanner and likely reflected reduced tissue oxygenation. In addition, a high-energy 
and oxygen-demanding process correlated with the $T_{2}$ changes: the magnitude and time course of the nucleus-to-cytoplasm translocation of high-mobility group box 1 (HMGB1), a molecule considered a sensor of cellular injury (Maroso et al., 2010), paralleled the degree and time course of MRI signal changes. Potential clinical applicability of the TLE-predictive MRI signal was tested using MRI sequences that detect the susceptibility effects $\left(\mathrm{T}_{2}{ }^{*}\right)$ directly. This approach enabled visualization of the predictive MRI signal using lower-field scanners.

\section{Materials and Methods}

Overview of experimental design. Experiments were conducted to address the following questions. Are there early MRI changes in the brain as a whole and/or in specific brain regions after experimental FSE? Are these changes unilateral, as described in children (VanLandingham et al., 1998; Shinnar et al., 2012; Lewis et al., 2014) and in our previous work in immature rodents (Dubé et al., 2004, 2009)? What is the relationship between early MRI changes and the emergence of epilepsy? To answer this first set of questions, a cohort of rats experiencing experimental FSE was imaged and then subjected to video EEG for 10-12 months and compared with a littermate control group. Because the TLE that arises after experimental FSE is characterized by sparse seizures and minimal cell loss (Toth et al., 1998; Bender et al., 2005; Dubé et al., 2006, 2010), we also investigated whether other functional and structural changes might distinguish the epileptic limbic network. To this end, we measured, in addition to seizures, epileptic spike series in hippocampal EEGs and hippocampal neuron dendritic toxicity. A second set of questions pertained to the relationship between the early MRI changes that were consistent with increased oxygen utilization by brain tissue and venous blood deoxyhemoglobin levels that might reflect such enhanced oxygen utilization. To study this question, a separate cohort of rats was imaged at $2 \mathrm{~h}$ after FSE and then killed for deoxyhemoglobin analyses for comparison with littermate control rats. A third query addressed the relationship between the early MRI changes and HMGB1 translocation to the cytoplasm. The latter is a high-energy-demanding process that might signify onset of inflammatory cascades. For this experiment, a cohort of immature rats, including experimental FSE and littermate controls, was imaged at $2 \mathrm{~h}$ and then the same rats were killed and perfused for HMGB1 expression and translocation analyses. Finally, we investigated whether the susceptibility changes found predictive using quantitiative $T_{2}$ maps acquired at high-field MRI could be visualized on lower-field MRI scanners using direct $\mathrm{T}_{2}{ }^{*}$ sequences. For this experiment, a separate cohort of rats, including those experiencing FSE and littermate controls, were imaged using $\mathrm{T}_{2}$ quantitative sequences on an $11.7 \mathrm{~T}$ scanner, followed by imaging on a $4.7 \mathrm{~T}$ scanner using $\mathrm{T}_{2}{ }^{*}$ sequences.

Animals and induction of experimental FSE. All experimental procedures were approved by University of California-Irvine or Loma Linda University Institutional Animal Care Committees and conformed to National Institutes of Health guidelines. Sprague Dawley-derived rats were maintained in quiet facilities under controlled temperatures and lightdark cycles. Cages were monitored every $12 \mathrm{~h}$ for the presence of pups and the date of birth was considered postnatal day 0 (P0). On P2, litters were culled to 10 pups, if needed. When weaned (on P21), rats were housed 2-3 per cage. Male rats were used.

Experimental FSE was induced as described previously (Chen et al., 1999; Dubé et al., 2004, 2010; Koyama et al., 2012). Briefly, on P10, pups were placed in a glass container and their core temperature, which is highly correlated with brain temperature (Dubé et al., 2005b), was increased to $\sim 40.5^{\circ} \mathrm{C}$ (simulating high fever) using a regulated stream of warm air. Core temperatures were measured at baseline, at seizure onset, and every 2 min during hyperthermia. Hyperthermic seizures manifest as characteristic behaviors: seizure onset is heralded by a sudden loss of motion (freezing), followed by oral automatisms and forelimb clonus. Seizures progress to body flexion with chewing of an extremity and one or more tonic stage 5 seizures (Racine, 1972). Hyperthermia $\left(39.5-41^{\circ} \mathrm{C}\right.$ ) was maintained for $\sim 40 \mathrm{~min}$ (Dubé et al., 2010), resulting in behavioral seizures lasting $31.0 \pm 0.35 \mathrm{~min}$.
Hyperthermic controls were littermates of the experimental rats and subjected to the same duration of hyperthermia, but seizures were prevented by treatment with pentobarbital (Nembutal $16-25 \mathrm{mg} / \mathrm{kg}$, i.p.) 30 min before induction of hyperthermia. An additional control group included littermates of the experimental group that were removed from the cage for the same duration (to control for potential stress) and their core temperatures kept within the normal range for age (normothermic controls).

MRI procedure and analysis. MRIs were performed on a Bruker Avance 11.7 T MR scanner and all quantitative $\mathrm{T}_{2}$ studies were performed on the same single scanner. Rats were anesthetized for the duration of the imaging using $1.5 \%$ isoflurane in $100 \% \mathrm{O}_{2}$ and body temperature was maintained at $\sim 36.5^{\circ} \mathrm{C}$ with a heated water cushion. A field-of-view of $2.3 \mathrm{~cm}$ and a slice thickness of $0.75 \mathrm{~mm}$ were used for all scans. $\mathrm{T}_{2}-$ weighted images were acquired using a $2 \mathrm{D}$ multi-echo-spin-echo sequence with the following parameters: $\mathrm{TR}=4697 \mathrm{~ms}, \mathrm{TE}=10.21-100.1$ $\mathrm{ms}$, inter-TE $=10.21 \mathrm{~ms}$, matrix size $=192 \times 192$, and number of averages $(\mathrm{NA})=2$. To determine the relationship between early $\mathrm{T}_{2}$ changes and epilepsy, "FSE"-sustaining rats were scanned serially at 2, 18, and $48 \mathrm{~h}$ after FSE $(n=19)$. Normothermic controls were scanned on P10 once $(n=8)$ or serially $(n=14)$. Hyperthermic controls $(n=14)$ were scanned $2 \mathrm{~h}$ after hyperthermia. Additional groups of rats (6 normothermic controls and 12 FSE) were imaged at both 2 and $4 \mathrm{~h}$ to determine the duration of the obtained signal changes. This sequence was also used to determine relationships between $\mathrm{T}_{2}$ and deoxyhemoglobin levels, as well as $\mathrm{T}_{2}$ and HMGB1 translocation.

To determine the relationship between high-field $\mathrm{T}_{2}$ changes and the deoxyhemoglobin-sensitive $\mathrm{T}_{2}{ }^{*}$ effect and to enable the visualization of predictive changes in clinically relevant MRI scanners, a separate rat cohort was imaged on a Bruker Avance 4.7 T MRI scanner and then at 11.7 $\mathrm{T}$ using the $\mathrm{T}_{2}$ sequence described in the preceding paragraph. Rats were scanned $2 \mathrm{~h}$ after FSE $(n=8)$ and compared with littermate controls $(n=7) . \mathrm{T}_{2}{ }^{*}$-weighted images were acquired with a multi-echo-gradientecho sequence with the following parameters: $\mathrm{TR}=500 \mathrm{~ms}$, flip angle $=$ $38.8^{\circ}$, TEs $=3.77-65.33 \mathrm{~ms}$, inter-TE $=6.84 \mathrm{~ms}$, matrix size $=128 \times$ 128 , and $\mathrm{NA}=16$. Absolute $\mathrm{T}_{2}$ or $\mathrm{T}_{2}{ }^{*}$ relaxation time values (in milliseconds) were calculated by log transform followed by a linear leastsquares fit on a pixel-by-pixel basis and $\mathrm{T}_{2}$ or $\mathrm{T}_{2}{ }^{*}$ maps were generated using in-house software (MATLAB RRID:nlx_153890; Mathworks). $\mathrm{T}_{2}$ measurements were consistent across the imaging sessions. For example, in the normothermic control rats $(n=22)$, whole-brain $\mathrm{T}_{2}$ across 6 imaging cohorts that spanned 18 months were as follows: cohort $1(n=4)$ was $58.1 \pm 0.57 \mathrm{~ms}$, cohort $2(n=3)$ was $59.9 \pm 1.26 \mathrm{~ms}$, cohort $3(n=3)$ was $57.8 \pm 1.7 \mathrm{~ms}$, cohort $4(n=4)$ was $57.9 \pm 0.96 \mathrm{~ms}$, cohort $5(n=3)$ was $58.3 \pm 0.17 \mathrm{~ms}$, and cohort 6 was $58.9 \pm 1.23 \mathrm{~ms}$ (mean $\pm \mathrm{SD}$ ). No significant differences were found among these groups $(F=1.59, p=0.22)$.

Images were coded and analyzed without knowledge of treatment group or time of imaging to ensure that there was no bias when the measurements were performed. Regions were delineated manually separately in the left and right hemispheres. MRI signal changes are most often unilateral and universally asymmetric in children after FSE and in adults with epilepsy after FSE. We have previously identified unilateral hippocampal changes on MRI (Dubé et al., 2009, 2010) in this model of FSE, similar to those observed in children with FSE. Therefore, we performed separate measurements and analyses of left and right amygdala, hippocampus, medial thalamus, and other bilateral limbic structures.

$\mathrm{T}_{2}$ values were measured using ImageJ software (version 1.25l, RRID: nif-0000-30467). The regions of interest were defined on gray scale maps and a dynamic range of $0-100 \mathrm{~ms}$ was used. For the figures (e.g., Fig. 1), we used a color map and reduced the dynamic range $(40-80 \mathrm{~ms})$ to highlight the differences among groups. In four rats (three control and one FSE), image artifacts prevented $\mathrm{T}_{2}{ }^{*}$ measurements in basolateral amygdala.

Because of the established unilateral or asymmetric nature of the epilepsy focus and the MRI changes after FSE-related epilepsy in humans and rodents, the lower side was analyzed for all of the groups and all of the comparisons.

EEG electrode implantation. One month after FSE ( $n=19$ FSE; 16 normothermic controls and 7 hyperthermic controls), bipolar electrodes 
(Plastics One) were implanted bilaterally in the hippocampus (AP: 3.3; L: 2.3 ; $\mathrm{V}:-2.8 \mathrm{~mm}$ with reference to bregma), a cortical electrode was placed over the parietal cortex (AP: $2 ; \mathrm{L}:-2 \mathrm{~mm}$ ), and a ground electrode over the cerebellar cortex. Cortical and hippocampal recordings were conducted in freely moving rats and electrode placement was verified post hoc.

Long-term digital video EEG recordings and analysis. Video EEG monitoring began $5 \mathrm{~d}$ after electrode implantation. EEG recordings were synchronized to video and conducted for a period of up to 10 months. EEG monitoring time was increased progressively to optimize seizure detection. Prior work in the same model indicated that epilepsy does not commence before a month after the inciting FSE and its incidence increases over the subsequent 2-8 months (Dubé et al., 2006, 2010); this is consistent with a long latent period in humans (French et al., 1993). Because of this and in view of limited recording capacity, we sampled progressively over the course of 10 months. In the first month, we monitored for $112 \mathrm{~h}(15.6 \%$ of a month), $180 \mathrm{~h}(25 \%)$ in the penultimate month, and $206 \mathrm{~h}(28.6 \%)$ in the final month. The recordings in the later months consisted of several segments of continuous 24/7 monitoring lasting 3-5 d, enabling sampling of circadian variability and of several consecutive days. Overall, $>37,000 \mathrm{~h}$ of video EEG were acquired, including $595 \pm 57 \mathrm{~h}$ per normothermic control rat, $430 \pm 41 \mathrm{~h}$ per hyperthermic control rat, and $1319 \pm 89 \mathrm{~h}$ per FSE rat.

EEGs were coded and scanned visually for spike series and seizures by two experienced investigators who were blinded to group identity (Dubé et al., 2010) and then reanalyzed using a seizure-detection software (LabChart version 7.3; ADInstruments). The concurrent video recordings were analyzed for behavioral manifestations of the apparent seizure. Only events with both EEG and behavioral changes and lasting $>20 \mathrm{~s}$ were classified as seizures. We evaluated typical behaviors associated with limbic seizures, including sudden cessation of activity, facial automatisms, head bobbing, prolonged immobility with staring, alternating or bilateral clonus, rearing, and falling (Racine, 1972). Rats were considered epileptic if they had at least one documented seizure as defined by these parameters. Spike series were defined as clusters of spikes with uniform interspike intervals. A cluster had a minimum of five spikes and lasted a minimum of 12 seconds.

Golgi method visualization and analysis of neuronal dendritic structure. Golgi impregnation and analysis were performed as described previously (Chen et al., 2004; Ivy et al., 2010). Hemispheres were immersed in Golgi-Cox solution for $10 \mathrm{~d}$, followed by a $2-5 \mathrm{~d}$ immersion in $30 \%$ sucrose, both in the dark. Using a vibratome, $200 \mu \mathrm{M}$ coronal sections containing dorsal hippocampus were mounted on coated slides and allowed to dry for 1-2 h. Sections were developed with $14 \%$ ammonium hydroxide for $30 \mathrm{~min}$, followed by $30 \mathrm{~min}$ in Kodak fixative. Sections were washed and dehydrated in increasing dilutions of ethanol and then coverslipped with Permount.

Fully impregnated neurons were sampled for this study without knowledge of treatment group. We were careful to pick neurons from a specific anatomical location within hippocampus to avoid potential confounders derived from location-dependent morphology of CA3 pyramidal cells. Neurons were sampled in dorsal CA3b within $150 \mu \mathrm{m}$ of the $\mathrm{CA} 3 \mathrm{~b} / \mathrm{CA} 3 \mathrm{c}$ boundary. Neurons were reconstructed in $2 \mathrm{D}$ using the camera lucida method without knowledge of treatment group (3-7 neurons per rat, 3-4 rats per treatment group). Dendritic arborization was analyzed using the Sholl method for dendritic complexity and length and compared among treatment groups.

Visualization and analysis of HMGB1 translocation. For this study, normothermic controls $(n=9)$ and FSE littermates $(n=24)$ were used. Rats were deeply anesthetized and transcardially perfused with $4 \%$ paraformaldehyde. Brains were removed, postfixed for $90 \mathrm{~min}$, and then cryoprotected in $30 \%$ sucrose. Free-floating sections were used for HMGB1 ICC using standard methods (Dubé et al., 2010) and rabbit anti-HMGB1 (1:1000, catalog \#ab18256, RRID: AB_444360; Abcam; Maroso et al., 2010). The reaction product was visualized using a 3,3'-diaminobezidine solution. Both the number of cells expressing HMGB1 and the proportion of these cells where HMGB1 was translocated from nucleus to cytoplasm en route to release were evaluated. HMGB1 translocation was considered absent when the immunoreactive (ir) product was confined to the nucleus. Translocation was considered present when HMGB1-ir filled the soma, and often also the dendrites, delineating the neuronal contour. All analyses were performed without knowledge of treatment group.

Measurements of venous blood deoxyhemoglobin. To determine the relationship between $\mathrm{T}_{2}$ and deoxyhemoglobin, a separate cohort of FSE $(n=12)$ rats and normothermic controls $(n=7)$ were imaged. One FSE rat was removed from analysis because of ventricular enlargement indicating a preexisting abnormality. Because of technical infeasibility of sampling venous cerebral blood and in view of the fact that cerebral metabolism accounts for $25-50 \%$ of total body oxygen consumption (Clarke and Sokoloff, 1999), deoxyhemoglobin analysis was performed on cardiac right ventricle blood. Sampling was performed immediately after MRI under terminal anesthesia and venous blood samples were placed on ice and analyzed within an hour. Briefly, using a 30 gauge needle connected to a heparinized syringe, $0.15-0.2 \mathrm{ml}$ of venous blood sample from the right cardiac ventricle was withdrawn, placed on ice, and analyzed using a hemoximeter (OSM3; Radiometer). Deoxyhemoglobin concentration was calculated using the following formula: deoxyhemoglobin concentration $=100-($ hemoglobin oxygen saturation + carboxyhemoglobin concentration + methemoglobin concentration).

Statistics. To determine whether MRI $\mathrm{T}_{2}$ values time course differed among groups, we performed two-way repeated measures ANOVA followed by post hoc analyses using $t$ tests with Bonferroni correction for multiple comparisons. Independent $t$ tests were used to compare the inciting FSE parameters (duration, number of stage 5 seizures, latency to onset from initiation of hyperthermia, seizure threshold temperature, and average core temperature during hyperthermia) of the rats that progressed on to epilepsy and those that did not. One-way ANOVA followed by the Tukey's post hoc test was used to determine the differences at $2 \mathrm{~h}$ among the FSE and normothermic and hyperthermic controls to investigate $\mathrm{T}_{2}$ in the hippocampus and amygdala among controls and nonepileptic and epileptic rats. To determine whether the $\mathrm{T}_{2}$ change was a result of localized regional changes, the same analyses were also performed on the predictive regions after normalization to individual whole-brain $\mathrm{T}_{2}$ values. To investigate the interrelationships between regional $\mathrm{T}_{2}$ changes, principal axis factor analysis with varimax rotation was used to derive underlying factors that could describe these regional patterns after FSE. Limbic regions (dorsal and ventral hippocampus, distinct amygdala nuclei, entorhinal cortex, piriform cortex) and limbic-interconnected regions (medial thalamus), as well as nonlimbic regions (cerebellum, corpus callosum) and extra-brain tissue (tongue muscle), were included. The Benjamini-Hochberg method was used to avoid false discovery.

For all bilateral regions in all groups, the lower of the two values were used (see detailed methodology in the MRI analysis section). Scree plots were examined to determine the number of derived factors,and factor scores for individual rats were obtained. In addition, the same analyses were performed for regional $\mathrm{T}_{2}$ values normalized to whole brain of individual rats. To determine whether MRI performed better than chance at predicting epilepsy after FSE, derived factor scores and regional MRI data from the FSE group underwent receiver operating characteristic (ROC) curve analyses. The area under curve (AUC) was then compared with chance $(A U C=0.5)$. Pearson correlation was used to determine the relationships among the values of $\mathrm{T}_{2}$ signals and deoxyhemoglobin levels, deoxyhemoglobin levels, and seizure duration, deoxyhemoglobin levels, and mean core temperature during the inciting seizure and between $\mathrm{T}_{2}$ values at $11.7 \mathrm{~T}$ and $\mathrm{T}_{2}{ }^{*}$ values at $4.7 \mathrm{~T}$. This was also calculated for the relationship between the 2 and $4 \mathrm{~h} \mathrm{~T}$ signals in the basolateral amygdala and the medial thalamus to determine whether the signal persisted. An independent $t$ test was used to determine whether the levels of blood hemoglobin were different between FSE rats and control rats. HMGB1 translocation analyses and dendritic complexity and length comparisons used one-way ANOVA with Bonferroni post hoc tests to correct for multiple comparisons.

Statistical analyses were performed using IBM SPSS software version 20.0. Graphs were generated using either SPSS or Prism version 5 software (GraphPad). Data are presented as mean \pm SEM unless otherwise stated and significance was set at $p<0.05$. 


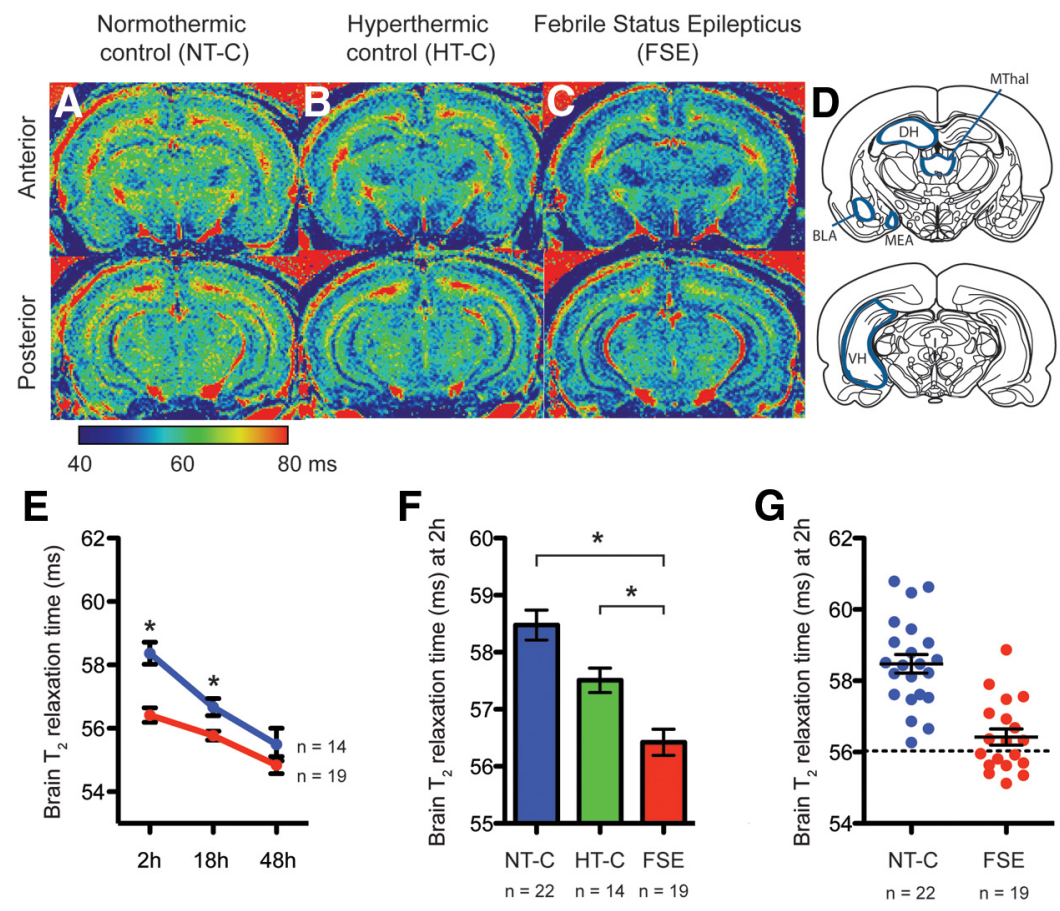

Figure 1. Brain $\mathrm{T}_{2}$ is reduced $2 \mathrm{~h}$ after FSE. $\boldsymbol{A}-\boldsymbol{C}$, Representative color-coded quantitative $\mathrm{T}_{2}$ maps $2 \mathrm{~h}$ after the end of hyperthermia from a normothermic $(\boldsymbol{A})$, hyperthermic $(\boldsymbol{B})$, and FSE $(\boldsymbol{C})$ rat. Note that the reduced $\mathrm{T}_{2}$ values occur across the entire brain in the FSE rat. $\boldsymbol{D}$, Regions of interest are highlighted on a rat atlas. $\boldsymbol{E}, T_{2}$ values time course after FSE and in normothermic 10-d-old control rats. A reduction of $\mathrm{T}_{2}$ values over the experimental period, characteristic of development, were observed in controls. $T_{2}$ decreased significantly in a time-dependent manner in FSE rats $(n=19)$ compared with controls $(n=14, F=4.11, p=0.035)$. The largest effect was observed $2 \mathrm{~h}$ after FSE $(p<0.001)$ and a significant effect was also observed at $18 \mathrm{~h}(p=0.007)$. Blue indicates normothermic control (NT-C) rats and red the FSE rats. Statistical significance was determined by repeated-measures ANOVA followed by post hoc analyses with $t$ tests that were adjusted for multiple-comparisons with Bonferroni's correction. $\boldsymbol{F}$ Seizures, not hyperthermia, led to the most robust $\mathrm{T}_{2}$ reduction. $\mathrm{T}_{2}$ values for the FSE group were significantly lower than those of either normothermic $(n=22, p<0.001)$ or hyperthermic $(n=14, p=0.014)$ control groups, indicating that brain $\mathrm{T}_{2}$ reductions in FSE rats resulted from hyperthermia-induced seizures and not from hyperthermia. Statistical significance was determined by ANOVA followed by post hoc analysis with Tukey's honestly significant differences (HSD) test. G, A subset of FSE rats had significantly lower brain $T_{2}$ values compared with the normothermic controls, which raised the possibility that the reduced $T_{2}$ values might predict epileptogenesis. $T_{2}$ values in 9 of 19 FSE rats lay more than 2 SDs from the normothermic controls. Dotted line indicates 2 SDs from mean of NT-C rats $(n=22)$. Circles indicate individual rats; blue circles are NT-C rats and red circles are FSE rats. Data are presented as mean \pm SEM. HT-C, Hyperthermic control; BLA, basolateral amygdala; MEA, medial amygdala; MThal, medial thalamus; DH, dorsal hippocampus; VH, ventral hippocampus. *Statistically significant at $p<0.05$.
(Ding et al., 2004; Dubé et al., 2004; Leppert et al., 2009; Oishi et al., 2013). To determine whether the reduced $\mathrm{T}_{2}$ values in FSE rats could be explained by differences in the inciting hyperthermia, we correlated the mean core temperature during hyperthermia to brain $\mathrm{T}_{2}$ in the FSE rats and found no significant relationship $(r=0.043, p=0.86)$. To consider possible influences of hyperthermia per se versus hyperthermia-induced seizures on $\mathrm{T}_{2}$, we included a group of rats that experienced hyperthermia while under anticonvulsant drugs (hyperthermic controls; Fig. 1A-C,F). Significant differences were found among groups $(F=$ 19.37, $p<0.001)$; post hoc analyses indicated that $\mathrm{T}_{2}$ values of rats experiencing both seizures and hyperthermia (FSE rats) were significantly lower than both normothermic and hyperthermic controls $(-2.06 \pm 0.33 \mathrm{~ms}, p<0.001$ and $-1.09 \pm$ $0.37 \mathrm{~ms}, p=0.014$, respectively).

\section{Reduction of whole-brain MRI $\mathrm{T}_{2}$ is confined to a subgroup of FSE rats} If $\mathrm{T}_{2}$ signal on MRI predicts epileptogenesis and only a subgroup of rats develop TLE, then two populations of FSE rats should emerge: those with normal and those with significantly abnormal $\mathrm{T}_{2}$ values. Therefore, we examined whole-brain $\mathrm{T}_{2}$ changes of individual rats and found that $\mathrm{T}_{2}$ values of 9 of 19 FSE rats fell outside of 2 SDs from the mean for normothermic controls (mean \pm 2 SDs: $58.48 \pm 2.45 \mathrm{~ms}, n=22$; Fig. $1 G)$. These findings raised the possibility that MRI might reflect individually distinct effects of FSE, which in turn might correlate with epileptogenesis.

\section{Results}

\section{Brain MRI $\mathrm{T}_{2}$ values after experimental FSE}

Using the high-magnetic-field MRI scanner, whole-brain $\mathrm{T}_{2}$ values of rats imaged longitudinally decreased with age, as reported previously (Dubé et al., 2004). In addition, as reported for immature and adult rodents, the absolute values of the relaxation times were compressed on the $11.7 \mathrm{~T}$ scanner compared with findings using lower-magnetic-field MR scanners: mean values were 59.7 ms versus $101.3 \mathrm{~ms}$ reported for immature rat controls at $6.3 \mathrm{~T}$ (Jansen et al., 2008) and $\sim 120 \mathrm{~ms}$ in P10 rats on a $4 \mathrm{~T}$ scanner (Dubé et al., 2004). These values were consistent with those reported in adult hippocampus by de Graaf et al. (2006): 72, 45.4, and $38.9 \mathrm{~ms}$ at field strengths of 4, 9.4, and $11.7 \mathrm{~T}$, respectively.

Comparing among groups, whole-brain $\mathrm{T}_{2}$ values of the total group of rats that underwent FSE were modestly lower than those of control littermates (interaction of time and group, $p=0.035$; Fig. 1). The greatest effect occurred at $2 \mathrm{~h}$ after FSE (mean difference $=-1.95 \pm 0.40 \mathrm{~ms}, p<0.001)$ and significant differences persisted at $18 \mathrm{~h}(-0.91 \pm 0.30 \mathrm{~ms}, p=0.007)$, but not at $48 \mathrm{~h}$ $(-0.65 \pm 0.54 \mathrm{~ms}, p=0.241)$. The typical developmental reduction in $\mathrm{T}_{2}$ relaxation values was observed in the control group

\section{Development of limbic epilepsy after experimental FSE}

Chronic video EEG monitoring was conducted for a period of up to 10 months. Prior work in our model indicated that epilepsy did not commence before a month after the insult (Dubé et al., 2006, 2010). Therefore, we sampled progressively over the course of 10 months: $15.6 \%$ of the time during the first month and $28.6 \%$ of time during the final month. The recordings in the later months consisted of several segments of continuous 24/7 monitoring lasting 3-5 d, enabling sampling of circadian variability and potential clustering during consecutive days. Overall, $>37,000 \mathrm{~h}$ of video EEG were acquired, including $595 \pm 57 \mathrm{~h}$ per normothermic control rat, $430 \pm 41 \mathrm{~h}$ per hyperthermic control rat, and $1319 \pm 89 \mathrm{~h}$ per FSE rat. Spontaneous seizures were detected in 6 of 19 rats after FSE (32\%), which is comparable to previous reports (Fig. 2, Table 1; Dubé et al., 2006, 2010) and to estimates in children (Hesdorffer et al., 2007). The epileptic rats had 0.07 seizures/d of recording, which, in view of the incomplete recording, is likely to be an underestimate of the true seizure rate. The sparse seizures (Table 1) are consistent with many epilepsies generated in immature rodents (Scantlebury et al., 2005) and the often sparse seizures in community based human studies (Lind- 


\section{A Parameters of the FSE}

i)

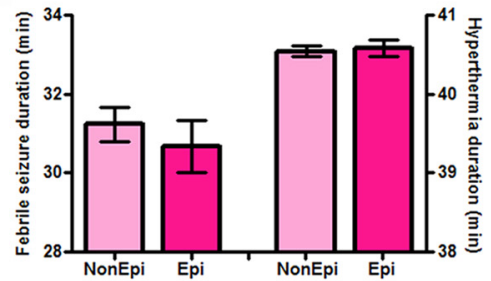

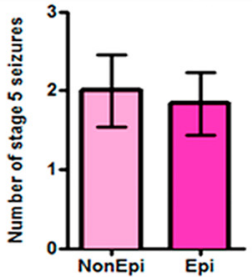

\section{B Representative seizure for each epileptic rat}
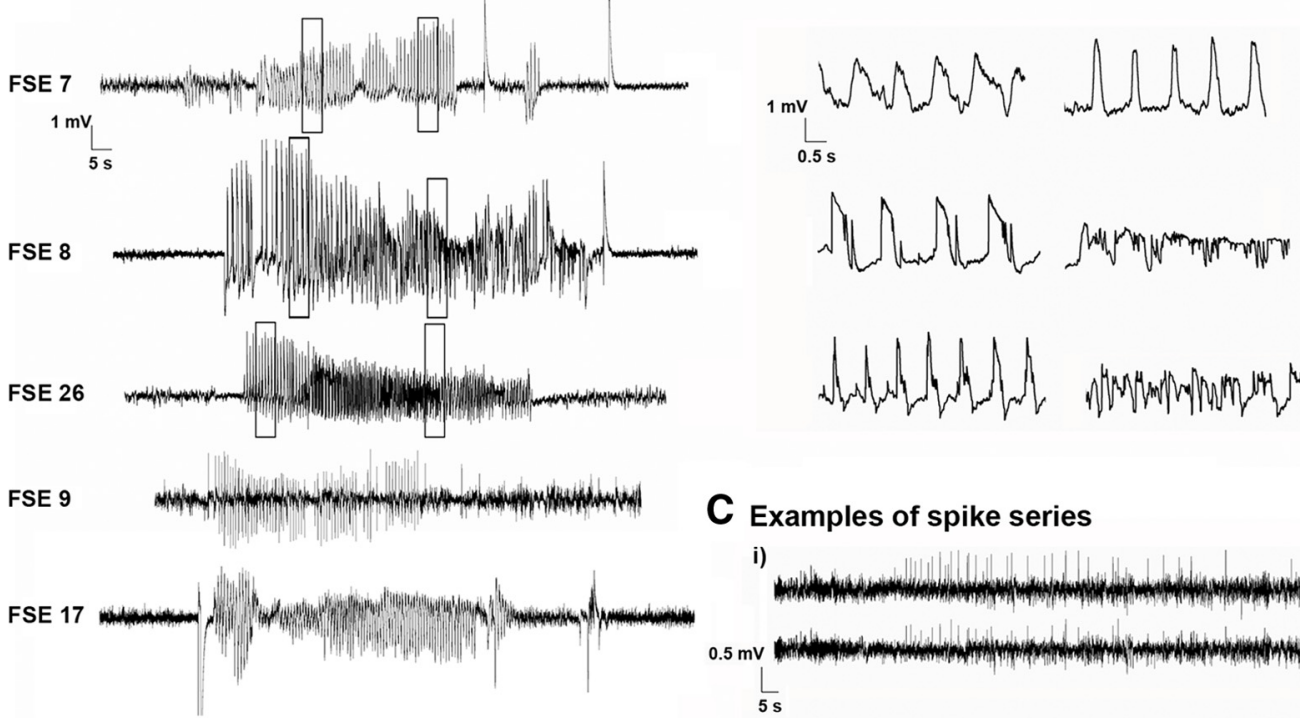

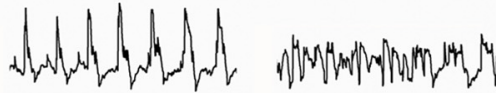

\section{Examples of spike series}

i)

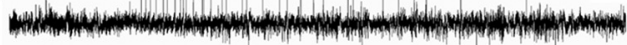

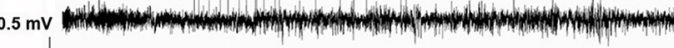

$5 \mathrm{~s}$

ii)

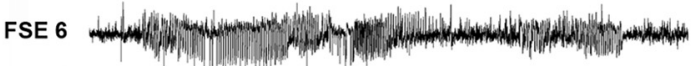

iii)

D Analysis of golgi impregnation

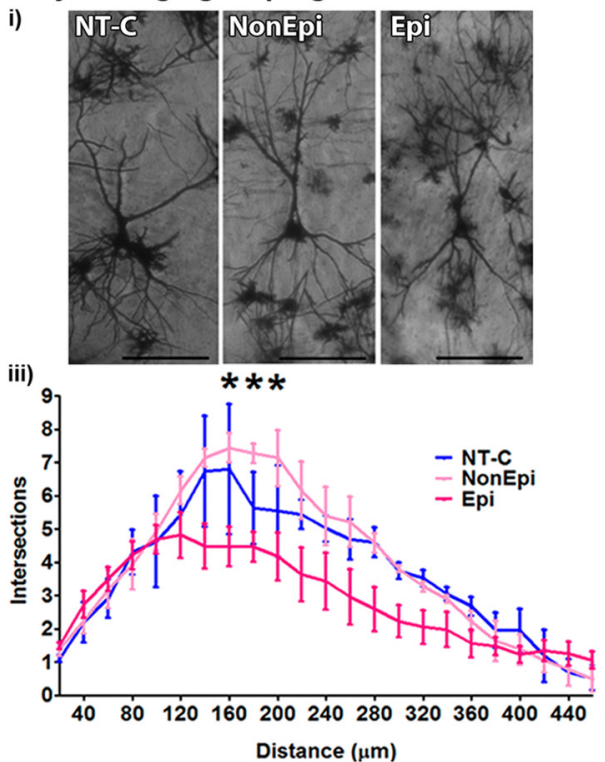

ii)

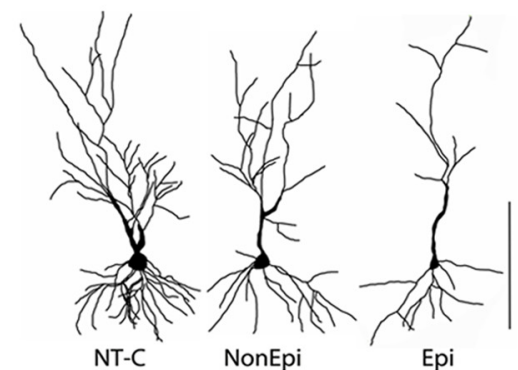

iv)

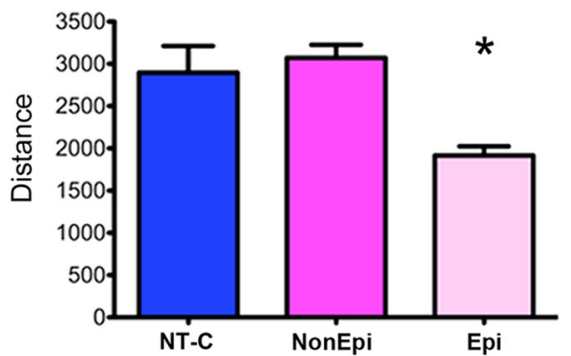

Figure 2. Severity and duration of the inciting FSE and the resulting epileptogenesis. Within the time frame of the experimental FSE, neither the duration of hyperthermia nor the duration of the seizures (Ai) or the number of stage 5 seizures during FSE (Aii) predicted which rats progressed on to epilepsy. Statistical significance was determined by independent samples $t$ test; nonepileptic $n=13$, epileptic $n=6$. Data are presented as mean \pm SEM. $\boldsymbol{B}$, Epilepsy was found in six of 19 rats and representative EEG traces of spontaneous seizures from each of the six epileptic rats are shown (see also Table 1). Areas in the boxes are shown in expanded time scales. C, Representative EEG traces from three epileptic rats with inter-ictal spike trains. These were observed in five epileptic rats. D, Hippocampal pyramidal cells from epileptic rats had reduced dendritic arborization compared with FSE rats not exhibiting spontaneous seizures (NonEpi) and with normothermic controls (NT-C). Shown are representative Golgi-impregnated sections (Di), traces of reconstructed dorsal hippocampus CA3b neurons (Dii), Sholl analysis of apical dendrites (Diii), and total dendritic length (Div). $n=3-4$ rats per treatment group. Data are presented as mean \pm SEM. NonEpi, nonepileptic; Epi, epileptic. 
Table 1. Characteristics of spontaneous limbic behavioral/electrographic seizures in adult epileptic rats

\begin{tabular}{|c|c|c|c|c|c|}
\hline Rat & $\begin{array}{l}\text { No. of seizures } \\
\text { Seizure duration (s) }\end{array}$ & Mean seizure duration (s) & Racine scale & Seizures/recording day & Number of spike trains cumulative duration (s) \\
\hline \multirow[t]{2}{*}{6} & $\begin{array}{l}4 \\
3627277723\end{array}$ & 64.5 & $2,2,2,2$ & 0.11 & 1 \\
\hline & $36,22,177,23$ & & & & 48 \\
\hline 7 & $95,145,220$ & & & & 2714 \\
\hline \multirow[t]{2}{*}{8} & 8 & 99.2 & $2,3,2,2,2,2,2,2$ & 0.16 & 3 \\
\hline & $154,57,85,93,223,60,26,96$ & & & & 148 \\
\hline \multirow[t]{2}{*}{17} & 4 & 87.2 & $2,2,2,2$ & 0.05 & 0 \\
\hline & $29,50,109,161$ & & & & \\
\hline \multirow[t]{2}{*}{26} & 3 & 84 & $2,2,3$ & 0.06 & 8 \\
\hline & $52,76,124$ & & & & 288 \\
\hline Mean & 3.8 & 95.1 & & 0.07 & Spike trains per rat: 5.3 ; mean duration: 108 s/train \\
\hline
\end{tabular}

say et al., 1979, Olafsson et al., 2005; Chong et al., 2013; Ablah et al., 2014). The number and duration of the seizures in the epileptic rats are shown in Table 1 and examples are found in Figure 2. The spontaneous seizures were limbic in semiology; associated with sudden freezing, facial automatisms, head nodding, and forelimb clonus (Racine stages $0-3$ ); and averaged $95.1 \pm 12.6 \mathrm{~s}$ in duration. Behavioral seizures coincided with ictal EEG activity that was detected in one or both hippocampal EEGs (Fig. 2, Table $1)$. Neither seizures nor spike series were detected in the normothermic $(n=16)$ or hyperthermic $(n=7)$ controls, nor in the $>10,000$ recorded hours in similar previous control cohorts.

The probability of developing epilepsy was not influenced by any parameter of the inciting hyperthermia or FSE (Fig. 2), including length of the hyperthermia (nonepileptic $40.67 \pm 0.42$ min; epileptic $40.46 \pm 0.24 \mathrm{~min} ; p=0.68$ ), length of the experimental FSE $(31.2 \pm 0.43 \mathrm{~min} ; 30.7 \pm 0.67 \mathrm{~min} ; p=0.48)$, number of stage 5 events $(2.0 \pm 0.45 ; 1.8 \pm 0.40 ; p=0.79)$, latency to onset of FSE from initiation of hyperthermia $(260 \pm 10.1 \mathrm{~s} ; 259 \pm$ $16.7 \mathrm{~s} ; p=0.99)$, threshold temperature $\left(40.47 \pm 0.26^{\circ} \mathrm{C}\right.$; $40.17 \pm 0.52^{\circ} \mathrm{C} ; p=0.62$ ), or average core temperature during hyperthermia $\left(40.5 \pm 0.07^{\circ} \mathrm{C} ; 40.6 \pm 0.1^{\circ} \mathrm{C} ; p=0.65\right)$. Because seizures in this model of FSE-related TLE are sparse, we searched for other parameters that might distinguish epileptic from nonepileptic rats. We studied epileptic spike trains and found them in five of six epileptic rats and in none of the controls (Table 1). In addition, we investigated whether the epileptic state was associated with structural changes in neurons within regions that participate in the seizures. Because spontaneous seizures were detected in hippocampus and dendritic toxicity has been found previously in this model (Toth et al., 1998; Bender et al., 2003), we analyzed dendritic structure in the pyramidal cell layer, focusing on CA3. A significant atrophy of dendritic trees in matched CA3b dorsal hippocampal pyramidal neurons was apparent in the FSEepileptic group compared with both normothermic controls and rats that did not become epileptic (Fig. 2D).

\section{Relationship between $T_{2}$ values in specific brain regions, but not in whole brain, and the development of epilepsy}

The results presented thus far demonstrated that experimental FSE led to significant decreases in $\mathrm{MRI}_{2}$ signal in a subgroup of rats and, in parallel, that limbic epilepsy developed in a subgroup of FSE rats. Therefore, we investigated whether the MRI changes $2 \mathrm{~h}$ after FSE were predictive of epilepsy in individual subjects. We found that neither whole-brain $\mathrm{T}_{2}$ values (mean difference from nonepileptic rats $=-0.32 \pm 0.56 \mathrm{~ms}, p=0.84$ ) nor $\mathrm{T}_{2}$ values in cranial muscles $(0.19 \pm 0.43 \mathrm{~ms}, p=0.90)$ distinguished the epileptic rats. These findings suggested that global, brainwide $T_{2}$ signal changes that might result from systemic processes do not predict epileptogenesis.

Because TLE involves the limbic circuit and because, in children, limbic $\mathrm{T}_{2}$ changes have been described in the context of FSE and TLE, we measured $T_{2}$ values of several limbic structures. We found asymmetry of $\mathrm{T}_{2}$ values between left and right hippocampus and amygdala, which is consistent with findings in children after FSE (VanLandingham et al., 1998; Shinnar et al., 2012; Lewis et al., 2014) and with our previous studies in the immature rodent FSE model (Dubé et al., 2009, 2010). Typically, the abnormal MRI delineates the location of the unilateral epilepsy focus in TLE (Lewis et al., 2014). Based on these facts, we focused on comparing, in all groups, the $\mathrm{T}_{2}$ values in the side with lower values. In individual rats, unilateral $\mathrm{T}_{2}$ values were reduced in FSE rats that became epileptic compared with those in rats that did not (Fig. $3 A-I)$. Specifically, $\mathrm{T}_{2}$ values in the basolateral amygdala of FSE rats that developed epilepsy were significantly lower than those in controls and in FSE nonepileptic rats (mean difference from controls $=-3.29 \pm 0.51 \mathrm{~ms}, p<0.001$; mean difference from nonepileptic rats $=-1.52 \pm 0.52 \mathrm{~ms}, p=0.017$; Fig. $3 G)$. A similar finding was obtained in medial amygdala $(-2.43 \pm 0.39 \mathrm{~ms}, p<$ $0.001 ;-0.99 \pm 0.39 \mathrm{~ms}, p=0.043$; Fig. $3 H)$. Using the Benjamini-Hochberg method to correct for the false discovery rate (potentially resulting from multiple comparisons) for the 6 tests conducted (basolateral amygdala, medial amygdala, medial thalamus, whole brain, dorsal and ventral hippocampus), the adjusted probabilities were as follows: basolateral amygdala, 0.03; medial amygdala, 0.084; medial thalamus, 0.1 ; whole brain, 0.648; dorsal hippocampus, 0.375; and ventral hippocampus, 0.93 . Whereas these changes were moderate in absolute terms, they represent a large effect size: Using Cohen's $d$, an established measure of effect size in which the threshold for a large effect is 0.8 , we found for the basolateral amygdala changes a Cohen's $d$ of 1.77 and for the medial amygdala $=1.32$. Hippocampal $\mathrm{T}_{2}$ values were also significantly reduced in epileptic compared with control rats (dorsal: $-2.96 \pm 0.67 \mathrm{~ms}, p<0.001$, Fig. 3I; ventral: $-2.26 \pm 0.55 \mathrm{~ms}, p<0.001)$. However, the values did not distinguish epileptic from nonepileptic rats $(-0.54 \pm 0.68 \mathrm{~ms}, p=$ $0.71 ; 0.6 \pm 0.55 \mathrm{~ms}, p=0.99$ ).

These analyses demonstrated that signal changes in specific brain regions, but not in the whole brain, distinguished epileptic and nonepileptic rats and suggested that the amygdala $\mathrm{T}_{2}$ values may be a predictive biomarker of epileptogenesis. Further support for the regional specificity of limbic signal derived from analysis of regional $T_{2}$ values normalized to the $T_{2}$ of whole brain 
in each animal (thus controlling for potential systemic or whole-brain confounders). Comparing epileptic with nonepileptic and control rats, we found that the basolateral amygdala $\mathrm{T}_{2}$ values ( $p=0.02$ and $p=0.024$, respectively) of epileptic rats remained significantly different from nonepileptic and control rats (Fig. $3 J$ ). In the medial thalamus, differences between the epileptic and control rats were still found $(p<0.001)$, but did not distinguish the epileptic from the nonepileptic rats $(p=0.44)$.

To determine objectively the efficacy of the amygdala $T_{2}$ values as a predictive marker of epilepsy after FSE, we used an independent unbiased measure, ROC curve analysis, which demonstrated that $\mathrm{T}_{2}$ values in both basolateral and medial amygdala $($ AUC $=0.91 \pm 0.08, p=0.005$; AUC $=0.82 \pm 0.10, p=0.028$, respectively; Fig. $3 \mathrm{~K}$ ) predicted epileptogenesis better than chance, as did $\mathrm{T}_{2}$ values in the medial thalamus $(\mathrm{AUC}=0.78 \pm 0.11$, $p=0.05$, Fig. $3 K$ ). Whole-brain (AUC $=$ $0.59 \pm 0.15, p=0.54)$, dorsal hippocampus (AUC $=0.67 \pm 0.17, p=0.25$ ), or ventral hippocampus values were not predictive (AUC $=0.49 \pm 0.14, p=0.93$; Fig. $3 L)$. Exploratory factor analysis followed by the ROC curve procedure was also performed on raw $\mathrm{T}_{2}$ values for limbic regions, as well as on values normalized to brain $T_{2}$ values of each animal (Tables 2, 3) and the differences remained robust.

Together, the region-of-interest approach (focused on limbic structures) and the independent unbiased mathematical approach (exploratory factor followed by ROC curve analyses) that reduced multiple comparisons (Tables 2,3) suggested that $\mathrm{T}_{2}$ signal reduction (using an $11.7 \mathrm{~T}$ magnet) in specific limbic brain regions and at $2 \mathrm{~h}$ after FSE are predictive of eventual limbic epilepsy. Therefore, we assessed the persistence of these changes, their origin, and their applicability to clinical settings. Assessing the persistence of the signal, we found that, by $18 \mathrm{~h}$, regional $\mathrm{T}_{2}$ signals no longer distinguished the epileptic and nonepileptic rats (mean difference of epileptic from nonepileptic rats in basolateral amygdala was $-1.03 \pm 0.92$ $\mathrm{ms}, p=0.17$; medial amygdala was $-0.74 \pm 0.41, p=0.12$; medial thalamus was $-0.36 \pm 0.47, p=0.45$; basolateral amygdala AUC $=0.29 \pm 0.14, p=0.15$; medial amygdala AUC $=$ $0.73 \pm 0.16, p=0.11$; medial thalamus AUC $=0.39 \pm 0.13, p=$ $0.43)$. Experiments using an additional rat cohort showed that the signal persisted $4 \mathrm{~h}$ after the experimental FSE (correlation between 2 and $4 \mathrm{~h} \mathrm{~T}_{2}$ values for basolateral amygdala $r=0.69, p=$ 0.002 , and medial thalamus $r=0.88, p<0.001$ ). These data suggested that the useful time window for detection of MRI sig-

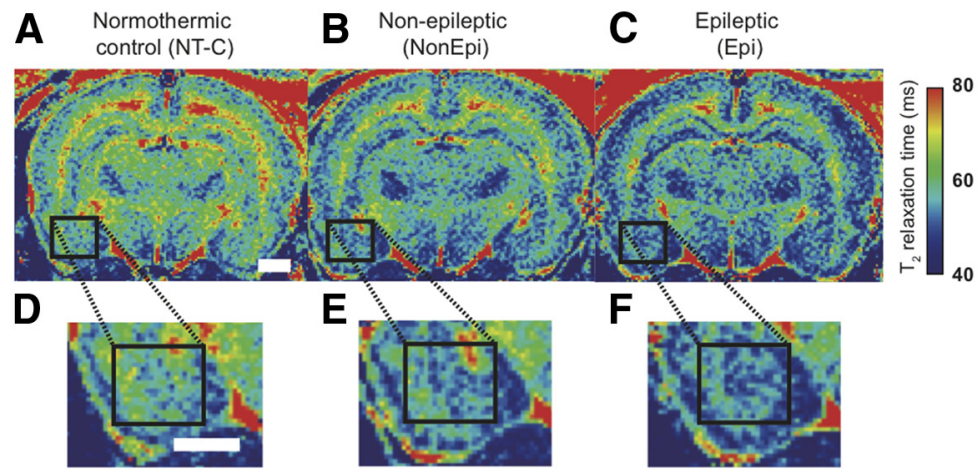

G Basolateral amygdala (BLA)

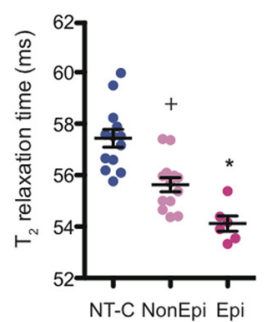

J

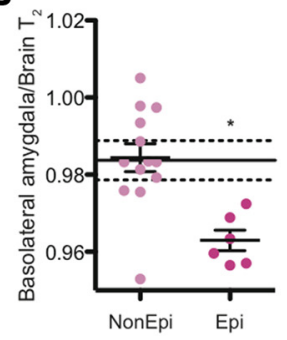

H Medial amygdala (MEA)

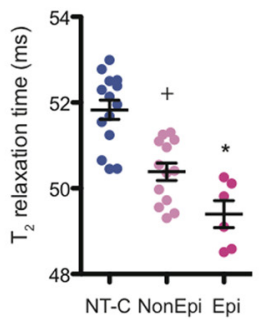

K

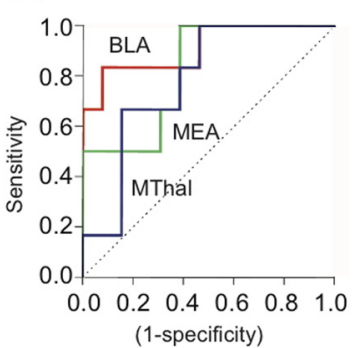

I Dorsal hippocampus (DHip)

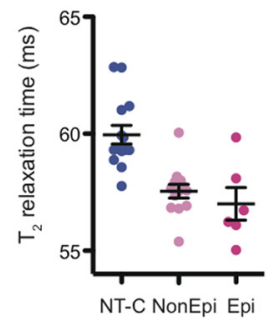

$\mathbf{L}$

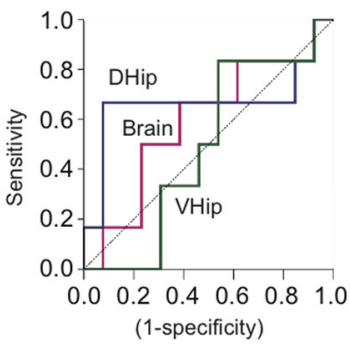

Figure 3. Amygdala $\mathrm{T}_{2}$ values $2 \mathrm{~h}$ after FSE distinguish rats that progressed on to epilepsy. $\boldsymbol{A}-\boldsymbol{F}$, Representative color-coded quantitative $\mathrm{T}_{2}$ maps of a normothermic control, a nonepileptic, and an epileptic FSE rat. Basolateral amygdala is highlighted in the black box. Scale bar indicates $1 \mathrm{~mm}$. $\mathrm{T}_{2}$ values in the basolateral amygdala $(\boldsymbol{A}-\boldsymbol{G})$ distinguished the epileptic group from the nonepileptic group, indicating that amygdala $\mathrm{T}_{2}$ values were predictive of epilepsy (epileptic group vs normothermic controls $p<$ 0.001 , epileptic group vs nonepileptic group $p=0.017)$. $\boldsymbol{H}$, Similar results were found for medial amygdala $(p<0.001$ and $p=$ 0.043).I, Hippocampal $\mathrm{T}_{2}$ did not distinguish epileptic from nonepileptic groups (dorsal hippocampus $p<0.001, p=0.71$, ventral hippocampus $p<0.001, p=0.99$ ). $J$, To exclude general or systemic effects, amygdala $\mathrm{T}_{2}$ values were normalized to total brain values. The normalized values, reflecting local changes in the basolateral amygdala, separated the epileptic rats from nonepileptic and control animals (epileptic vs nonepileptic rats $p=0.02$, epileptic vs control $p=0.024$; black line signifies the mean of the controls and dotted line the SEM of controls). $K$, ROCs for limbic structures and brain $\mathrm{T}_{2}$ values from the FSE rats indicated that amygdala and medial thalamus predicted epilepsy (BLA: $A U C=0.91 \pm 0.08, p=0.005$, MEA $0.82 \pm 0.10, p=0.028$, MThal $0.78 \pm 0.11, p=0.05)$. $L$, Neither hippocampal regions nor brain $\mathrm{T}_{2}$ predicted epilepsy any better than chance (dorsal hippocampus: $0.67 \pm 0.17, p=0.25$; ventral hippocampus: $0.49 \pm 0.14, p=0.93$; brain: $0.59 \pm 0.15, p=0.54$ ). Ideally, a predictive marker will have a high sensitivity (near $1.0 ; y$-axis) and specificity ([1-specificity] near zero; $x$-axis). Dotted line indicates AUC of 0.5 , a reference to chance. Statistical significance was determined by ANOVA followed by post hoc analysis with Tukey's HSD. Data are presented as mean \pm SEM. Values were compared among the sides with lower $\mathrm{T}_{2}$ values in all rats and all groups. NT-C, Normothermic control; NonEpi, nonepileptic; Epi, epileptic; BLA, basolateral amygdala; MEA, medial amygdala; MThal, medial thalamus; DH, dorsal hippocampus; VH, ventral hippocampus. Normothermic controls $n=14$, nonepileptic group $n=13$, epileptic group $n=6$. * Statistically significant at $p<0.05$.

nals that predicted epileptogenesis was $\sim 2-4 \mathrm{~h}$ after the termination of FSE.

\section{Relationship of the observed reduction in $\mathrm{T}_{2}$ values at very-} high-field MRI and increased deoxyhemoglobin levels

$\mathrm{T}_{2}$ reduction on MRI can be caused by paramagnetic substances, including oxygen-poor, unsaturated hemoglobin, which induce local susceptibility effects. These effects, leading to reduced $T_{2}$ values, are proportional to magnetic field strength and our studies used a high-field, 11.7 T magnet (Fig. 4A). Therefore, we investigated 
Table 2. Exploratory factor analysis on $\mathrm{T}_{2}$ values revealed distinct patterns that predicted epilepsy

\begin{tabular}{lccc}
\hline & Factor & \\
\cline { 2 - 4 } Region & 1 & 2 & 3 \\
\hline Entorhinal cortex & 0.89 & & \\
Dorsal hippocampus & 0.74 & 0.51 & \\
Piriform cortex & 0.65 & & \\
Cerebellum & 0.63 & 0.83 & \\
Medial amygdala & & 0.80 & 0.76 \\
Basolateral amygdala & & 0.80 & 0.71 \\
Medial thalamus & & & 18.58 \\
Muscle & 0.63 & 0.52 & $0.35 \pm 0.13$ \\
Ventral hippocampus & & 27.61 & 0.29 \\
Corpus callosum & 28.15 & $0.91 \pm 0.07$ & \\
Variance (\%) & $0.5 \pm 0.18$ & 0.005 & \\
ROC curve AUC & 1.0 & & \\
$p$-value &
\end{tabular}

$\mathrm{T}_{2}$ values of the lower side in all groups and all bilateral regions were analyzed together using exploratory factor analysis to identify possible patterns of $\mathrm{T}_{2}$ changes. Three patterns (factors) were identified. Notably, factor 2 was highly represented by the basolateral and medial amygdala and the medial thalamus. For clarity, loadings $<0.5$ are not shown. Factor scores were then derived and ROC curve analysis was performed, indicating that factor 2 was predictive of epilepsy. Nonepileptic group, $n=13$; epileptic group, $n=6$.

Table 3. Exploratory factor analysis on $\mathrm{T}_{2}$ values that were normalized to brain $\mathrm{T}_{2}$ revealed distinct patterns that were similar to raw $T_{2}$ values

\begin{tabular}{lllc}
\hline & Factor & 3 \\
\cline { 2 - 4 } Region & 1 & 2 & \\
\hline Medial amygdala & 0.84 & & \\
Basolateral amygdala & 0.75 & & \\
Medial thalamus & 0.75 & 0.87 & \\
Piriform cortex & & 0.74 & \\
Ventral hippocampus & & 0.73 & 0.74 \\
Entorhinal cortex & & & 0.59 \\
Dorsal hippocampus & & & 16.11 \\
Muscle & & & $0.39 \pm 0.13$ \\
Cerebellum & & 21.09 & 0.48 \\
Corpus callosum & 21.61 & $0.56 \pm 0.13$ & \\
Variance (\%) & $0.89 \pm 0.08$ & 0.66 & \\
ROC curve AUC & 0.009 & & \\
$p$-value & & & \\
\hline
\end{tabular}

To remove possible systemic effects that could influence the regional $T_{2}$ measurements, each region was normalized to the whole-brain $\mathrm{T}_{2}$ value for each rat and exploratory factor analysis was performed to identify possible patterns. Three patterns (factors) were found, indicating that certain regions changed together. Notably, factor 1 was highly represented by the basolateral and medial amygdala and the medial thalamus. This was a similar pattern of changes identified without normalization for systemic effects, suggesting that, after FSE, these regions tend to change together. For clarity, loadings $<0.5$ are not shown. Factor scores were then derived and ROC curve analysis was performed, indicating that factor 1was predictive of epilepsy. Nonepileptic group, $n=13$; epileptic group, $n=6$.

whether the reduced $\mathrm{T}_{2}$ values might result from enhanced oxygen utilization that endured beyond the FSE itself and the consequent increase in deoxyhemoglobin levels. In a separate cohort, we measured venous blood deoxyhemoglobin levels and correlated these with brain and extracranial muscle $\mathrm{T}_{2}$ values in the same individual rats of both control and FSE groups. $\mathrm{T}_{2}$ measurements in brain correlated strongly with deoxyhemoglobin levels $(r=-0.73 ; p=0.001)$, suggesting that increased deoxyhemoglobin contributed to the $\mathrm{T}_{2}$ decrease after FSE (Fig. 4B). A weaker correlation was obtained for extracranial muscle $\mathrm{T}_{2}$ and deoxyhemoglobin $(r=-0.47 ; p=0.057)$. These correlations pertain to systemic venous blood because we failed technically to obtain sufficient quantities of cerebral venous blood to measure reliably hemoglobin levels. However, at the developmental ages examined here, $25-50 \%$ of oxygen utilization involves cerebral metabolism (Clarke et al., 1999). The robust correlation obtained here between venous blood and $\mathrm{T}_{2}$ probably underestimated the contribution of cerebral venous deoxyhemoglobin to the reduced $\mathrm{T}_{2}$ relaxation times.
A

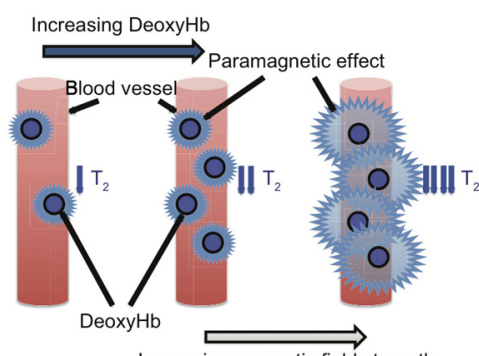

Increasing magnetic field strength

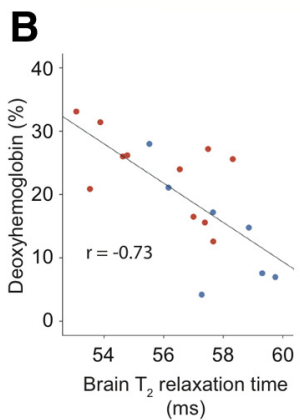

C

Figure 4. Reduced $T_{2}$ values after FSE correlate with increased deoxyhemoglobin levels. $\boldsymbol{A}$, $\mathrm{T}_{2}$ values were likely reduced because of a paramagnetic effect of deoxyhemoglobin and increased levels of unsaturated (deoxy)hemoglobin after FSE. This paramagnetic effect increases as a function of magnetic field strength. Significant correlation of reduced brain $(\boldsymbol{B})$ and muscle (C) $\mathrm{T}_{2}$ values with increased blood deoxyhemoglobin levels $(-0.73, p=0.001 ;-0.47, p=$ 0.057 , respectively). Values were compared among the sides with lower $\mathrm{T}_{2}$ values in all rats and all groups. Shown is a scatter plot of individual rats, with blue circles indicating normothermic control rats $(n=7)$ and red circles the FSE rats $(n=11)$.

Neither mean core temperature nor duration of the inciting febrile seizures correlated with deoxyhemoglobin levels, excluding the possibility that the increased deoxyhemoglobin could be a result of overt differences in the inciting hyperthermia and seizures $(r=-0.48, p=0.89 ; r=-0.11, p=0.76$, respectively). Notably, total hemoglobin levels did not differ between the groups (control $10.83 \pm 0.24 \mathrm{~g} / \mathrm{dL}$ and FSE $10.98 \pm 0.34 \mathrm{~g} / \mathrm{dL}$, $p=0.72$, respectively).

Early, energy-demanding inflammatory processes correlate with the MRI changes in a subset of FSE subjects

Several factors might result in increased deoxygenated hemoglobin levels and these often involve a mismatch between blood supply and tissue metabolic rates (Pereira de Vasconcelos et al., 2002; Schridde et al., 2008; DeSalvo et al., 2010). Here, we tested the idea that the increased deoxygenated hemoglobin derived from augmented oxygen extraction resulting from energydemanding cellular processes and that these in turn may signify the initial steps in the epileptogenic cascade. We focused on inflammatory mechanisms because they have been implicated in the epilepsy that follows experimental FSE (Dubé et al., 2005a, 2010) and in TLE in general (Vezzani et al., 2011). An early step initiating inflammatory processes in the brain is the translocation of the HMGB1 molecule from the nucleus into the cytoplasm, which is followed by its release out of the cell. This high-energydemanding process takes place in response to cellular injury and leads to binding of HMGB1 to toll-like receptors and others (Maroso et al., 2010; Vezzani et al., 2011). Therefore, we investigated whether HMGB1 translocation might account for augmented oxygen extraction and deoxyhemoglobin levels, generating the decreased $\mathrm{T}_{2}$ effect observed in the amygdala of the subset of FSE rats that became epileptic. To this end, a separate cohort of rats 
was divided into normothermic controls and FSE, subjected to MRI at $2 \mathrm{~h}$, and then killed for assessment of HMGB1 expression and translocation (Fig. 5). The number of cells expressing HMGB1 within the nucleus did not differ appreciably among groups (Fig. 5A,B). However, HMGB1 translocation to the cytoplasm, a preamble to its release, was largely confined to the FSE group (Fig. $5 B$ ) and was correlated with the reduction in $\mathrm{T}_{2}$ values (Fig. 5D). The temporal evolution of HMGB1 translocation was also highly congruent with the time course of the $\mathrm{T}_{2}$ signal changes (Fig. 5C).

\section{Assessing the MRI signal changes using clinically relevant, lower-field MRI}

The epilepsy-predicting MRI signal changes described in the previous section were obtained using a high-field scanner that was chosen to maximize signal-tonoise ratios. These are crucial for imaging small samples such as immature rat brain, which have a volume of $\sim 0.5 \mathrm{~cm}^{3} \mathrm{com}$ pared with $\sim 1000 \mathrm{~cm}^{3}$ for human infants. Once we discovered the predictive value of reduced MRI $\mathrm{T}_{2}$ values at high magnetic fields and their relationship with increased deoxyhemoglobin levels, we used this information to seek imaging parameters that would enable detection of epilepsy-predictive MRI changes at lower magnetic fields. Specifically, we imaged individual rats using both the $\mathrm{T}_{2}$ sequence at $11.7 \mathrm{~T}$ and a deoxyhemoglobinsensitive $\mathrm{T}_{2}{ }^{*}$ sequence (Fig. 6) using a 4.7 $\mathrm{T}$ scanner. The latter method, used in functional MRI studies, is feasible in lowmagnetic-field MRI scanners used in clinical settings. At $2 \mathrm{~h}$ after FSE, low-field $\mathrm{T}_{2}{ }^{*}$ measurements and high-field $\mathrm{T}_{2}$ measurements identified the same rats, with strong correlations between the 2 methods for the region predictive of epilepsy (basolateral amygdala $r=0.751, p=$ 0.008; medial thalamus $r=0.846, p<$ 0.001; Fig. $6 G, H)$. These findings indicate that the predictive signal changes observed using high-field MRI scanners can be detected using more clinically relevant MRI scanners.

\section{Discussion}

The principal discovery in these studies is the identification of a novel, noninvasive, and predictive marker of limbic epilepsy after experimental FSE, which suggests salient biological processes and is potentially translatable to the clinical setting. Specifically, on high-magnetic-field scanners, reductions in MRI $\mathrm{T}_{2}$ relaxation times in amygdala that are detectable hours after FSE predict which rats will develop epilepsy in the ensuing months. The reduced $\mathrm{T}_{2}$ values may derive from increased deoxyhemoglobin levels - consistent with augmented oxygen utilization in limbic
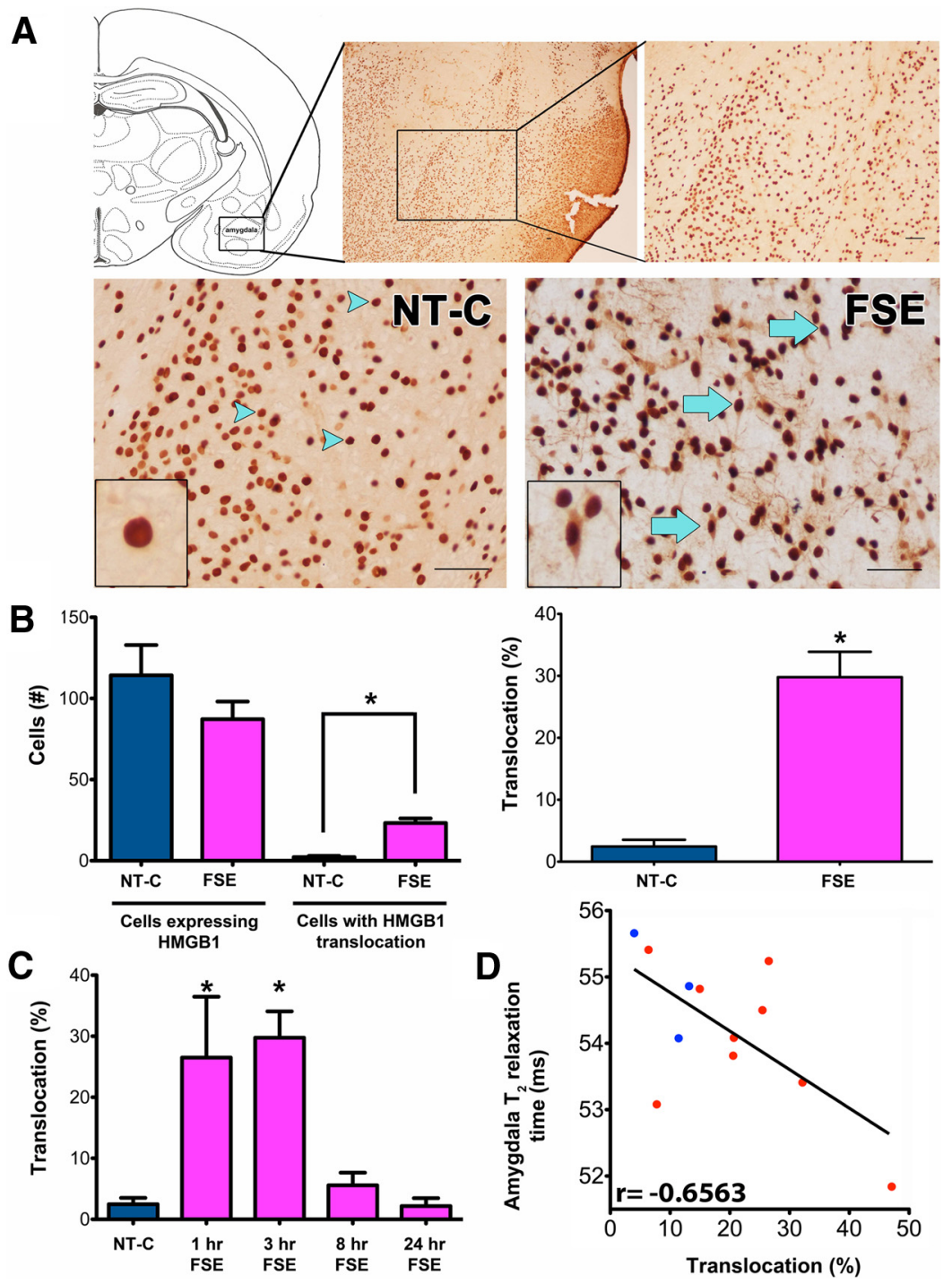

Figure 5. Translocation of HMGB1 from the nucleus to the cytoplasm in amygdala neurons correlates with lowered $\mathrm{T}_{2}$ signal on MRI. $\boldsymbol{A}$, Representative photomicrographs of immunocytochemistry for HMGB1. Top, Identification of basal amygdala. Bottom, Differences in HMGB1 localization between normothermic control (NT-C) and experimental FSE rats. Arrowheads indicate nuclear HMGB1 and arrows indicate cytoplasmic (translocated) HMGB1. B, Quantitative analysis of HMGB1 expression and localization at $3 \mathrm{~h}$ after the end of FSE showed that, whereas the number of HMGB1 expressing cells was not influenced by the occurrence of FSE, the cytoplasmic localization of HMGB1 was significantly higher in sections from FSE compared with NT-C subjects (left graph; NT-C $n=3$, FSE $n=3)$. Similar results were obtained when data were represented as a percentage of cells with translocated HMGB1 over total HMGB1-positive cells (right graph). C, Time course of HMGB1 translocation after FSE demonstrates the transient nature of this early inflammatory process: the localization pattern in amygdala sections from FSE rats resembled that of NT-C sections by $8 \mathrm{~h}$ after the end of FSE. Blue indicates NT-C, $n=3$; magenta is FSE at the time points indicated ( $n=3$ per time point). $\boldsymbol{D}$, Significant correlation of reduced amygdala $\mathrm{T}_{2}$ values with increased HMGB1 translocation (NT-C, in blue, $n=3$; FSE, in red, $n=$ $9 ; p=0.02$ ). Values were compared among the sides with lower $T_{2}$ values in all rats and all groups. Data are presented as mean \pm SEM. Scale bars, $100 \mu \mathrm{m}$. *Statistically significant at $p<0.05$.

brain regions - that persists for hours after the inciting FSE. The mechanisms requiring oxygen may include the energy-demanding translocation of the proinflammatory danger-signal molecule HMGB1 from the nucleus to the cytoplasm, likely followed by its release and an initiation of a cytokine response. Finally, these predictive MRI changes are also observable using $\mathrm{T}_{2}{ }^{*}$ sequences at field strengths applicable to human imaging.

Timing, imaging sequences, and MRI field strength influence signal changes after FSE in immature brain

Using high-field, high-resolution MRI imaging, we found that a subset of rats experiencing FSE developed brain changes that 
A

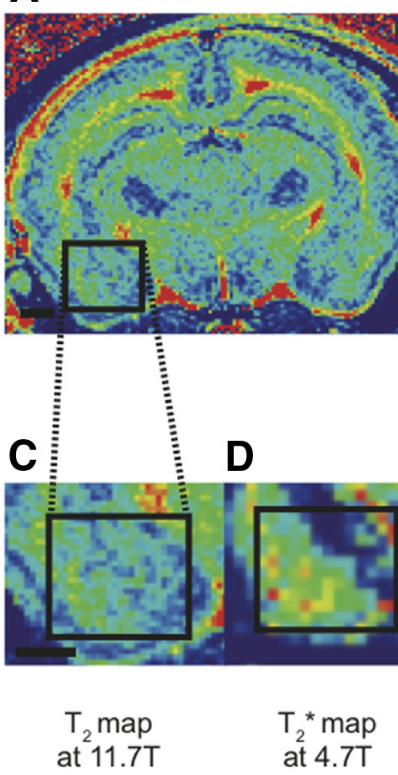

B FSE

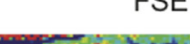

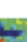

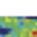

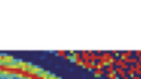
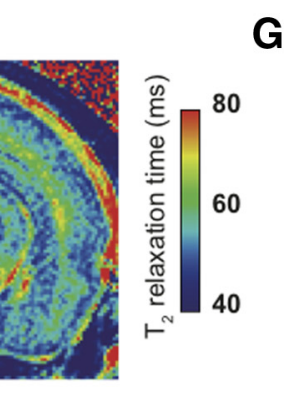
immature rodents and age has a profound influence on the nature of brain injury provoked by severe seizures (Nitecka et al., 1984; Holmes and Thompson, 1988; Jensen et al., 1991; Sperber et al., 1992; Stafstrom et al., 1992; Toth et al., 1998; Kubová et al., 2001; Lee et al., 2001; Raol et al., 2003; Baram et al., 2011). We also aimed to recreate the human insult of FSE, that is, long seizures provoked by combined temperature elevation and inflammatory cytokines induced by fever (Dubé et al., 2005a, 2010; Vezzani et al., 2011). Age and type of insult may underlie the unilateral limbic changes found in the present study and their resemblence to those in children.

\section{Basis of reduced $\mathrm{T}_{2}$ values using very-high-field MRI}

Our findings suggested increased levels of deoxygenated hemoglobin as a source of the paramagnetic effects that manifest as reduced $\mathrm{T}_{2}$ on high-field MRI scanners. Augmented deoxyhemoglobin reflects a mismatch between tissue oxygen demand and supply and is governed by numerous factors, including cerebral blood flow, cerebral blood volume, and oxygen extraction fraction (van Zijl et al., 1998; Schridde et al., 2008; DeSalvo et al., 2010; Goense et al., 2012). We excluded subtle seizures during the MRI as potential bases for ongoing increased oxygen demand uncompensated by blood supply because MRIs were acquired under isoflurane anesthesia, a potent anticonvulsant (Mirsattari et al., 2004). We identified an energetically demanding process, an early "upstream" step in the inflammatory cascade already implicated in FSE (Dubé et al., 2010; Kovac et al., 2012). The correlation of the magnitude and time course of HMGB1 translocation with $\mathrm{T}_{2}$ changes supported a role for these processes in increased cellular energy and oxygen demand resulting in augmented deoxyhemoglobin levels, although other potential processes were not excluded (Folbergrová et al., 1985; Young et al., 1987; Lothman, 1990; Hascoet et al., 1988; Schridde et al., 2008; Varghese et al., 2009; DeSalvo et al., 2010).

Significant and predictive MRI $\mathrm{T}_{2}$ signal differences between rats that developed epilepsy and those that remained nonepileptic were in amygdala and, using factor analysis, in combined medial-thalamus/amygdala. The involvement of these regions is intriguing. First, acute amygdala and thalamic MRI abnormalities have been observed in a subset of children after FSE (Natsume et al., 2007; Shinnar et al., 2012) and their atrophy was more severe in TLE patients with a history of FSE compared with those without (Cendes et al., 1993a; Dreifuss et al., 2001; Bernhardt et al., 2012). Amygdala and limbic thalamus constitute important components of an excitatory circuit involved in TLE in humans and rodents (Gloor et al., 1982; Tremblay and Ben-Ari, 1984; Cassidy and Gale, 1998; Blumenfeld et al., 2004; Englot et al., 2009). Amygdala is one of the most excitable brain regions (Goddard et al., 1969) and is a region of onset of kainate-induced seizures (Tremblay and Ben-Ari, 1984) and of FSE (Baram et al., 1997) in immature rats. Amygdala and medial thalamus may be particularly susceptible to mismatches between oxygen supply and demand, especially in immature brain (Fujikawa et al., 1986; Kubová et al., 2001; Pereira de Vasconcelos et al., 2002; Wasterlain et al., 2010). Indeed, we found amygdala and hippocampal neuronal injury after experimental FSE (Toth et al., 1998).

\section{Potential clinical application of these findings}

Human MRI studies typically use 1.5-3 T scanners. To explore potential clinical application of our findings, we used a sequence that is more sensitive to deoxyhemoglobin and is readily available in clinical settings - a quantitative $\mathrm{T}_{2}{ }^{*}$ sequence. The predictive effects were reproduced on a $4.7 \mathrm{~T}$ scanner, which was not sur- prising because changes in deoxyhemoglobin levels that are detectable using $\mathrm{T}_{2}{ }^{*}$ imaging are widely exploited as a basis for functional MRI (Ogawa et al., 1990; Dinstein et al., 2012), often using 1.5 T scanners (Dosenbach et al., 2010). Therefore, the predictive signal changes found here should also be readily detectable on standard clinical MRIs.

In summary, using an animal model of FSE; high-resolution, high-field MRI; chronic video EEG; neurochemical blood analyses; and molecular and neuroanatomical approaches, we defined an early, noninvasive, predictive marker of epileptogenesis. Because the changes were visible on clinically relevant scanners, we propose that this MRI signature be tested for its efficacy in predicting FSE-related TLE in the clinical setting.

\section{References}

Ablah E, Hesdorffer DC, Liu Y, Paschal AM, Hawley S, Thurman D, Hauser WA; Prevalence of Epilepsy in Rural Kansas Study Group (2014) Prevalence of epilepsy in rural Kansas. Epilepsy Res 108:792-801. CrossRef Medline

Annegers JF, Hauser WA, Shirts SB, Kurland LT (1987) Factors prognostic of unprovoked seizures after febrile convulsions. N Engl J Med 316:493498. CrossRef Medline

Avishai-Eliner S, Brunson KL, Sandman CA, Baram TZ (2002) Stressedout, or in (utero)? Trends Neurosci 25:518-524. CrossRef Medline

Baram TZ, Gerth A, Schultz L (1997) Febrile seizures: an appropriate-aged model suitable for long-term studies. Brain Res Dev Brain Res 98:265270. CrossRef Medline

Baram TZ, Jensen FE, Brooks-Kayal A (2011) Does acquired epileptogenesis in the immature brain require neuronal death? Epilepsy Curr 11:21-26. CrossRef Medline

Bender RA, Dubé C, Gonzalez-Vega R, Mina EW, Baram TZ (2003) Mossy fiber plasticity and enhanced hippocampal excitability, without hippocampal cell loss or altered neurogenesis, in an animal model of prolonged febrile seizures. Hippocampus 13:399-412. CrossRef Medline

Bender RA, Galindo R, Mameli M, Gonzalez-Vega R, Valenzuela CF, Baram TZ (2005) Synchronized network activity in developing rat hippocampus involves regional hyperpolarization-activated cyclic nucleotide-gated (HCN) channel function. Eur J Neurosci 22:2669-2674. CrossRef Medline

Bernhardt BC, Bernasconi N, Kim H, Bernasconi A (2012) Mapping thalamocortical network pathology in temporal lobe epilepsy. Neurology 78:129-136. CrossRef Medline

Blumenfeld H, McNally KA, Vanderhill SD, Paige AL, Chung R, Davis K, Norden AD, Stokking R, Studholme C, Novotny EJ Jr, Zubal IG, Spencer SS (2004) Positive and negative network correlations in temporal lobe epilepsy. Cereb Cortex 14:892-902. CrossRef Medline

Bouilleret V, Nehlig A, Marescaux C, Namer IJ (2000) Magnetic resonance imaging follow-up of progressive hippocampal changes in a mouse model of mesial temporal lobe epilepsy. Epilepsia 41:642-650. CrossRef Medline

Calamante F, Lythgoe MF, Pell GS, Thomas DL, King MD, Busza AL, Sotak CH, Williams SR, Ordidge RJ, Gadian DG (1999) Early changes in water diffusion, perfusion, T1, and T2 during focal cerebral ischemia in the rat studied at 8.5 T. Magn Reson Med 41:479-485. CrossRef Medline

Cassidy RM, Gale K (1998) Mediodorsal thalamus plays a critical role in the development of limbic motor seizures. J Neurosci 18:9002-9009. Medline

Cendes F, Andermann F, Gloor P, Lopes-Cendes I, Andermann E, Melanson D, Jones-Gotman M, Robitaille Y, Evans A, Peters T (1993a) Atrophy of mesial structures in patients with temporal lobe epilepsy: cause or consequence of repeated seizures? Ann Neurol 34:795-801. CrossRef Medline

Cendes F, Andermann F, Dubeau F, Gloor P, Evans A, Jones-Gotman M, Olivier A, Andermann E, Robitaille Y, Lopes-Cendes I (1993b) Early childhood prolonged febrile convulsions, atrophy and sclerosis of mesial structures, and temporal lobe epilepsy: an MRI volumetric study. Neurology 43:1083-1087. CrossRef Medline

Chen K, Baram TZ, Soltesz I (1999) Febrile seizures in the developing brain result in persistent modification of neuronal excitability in limbic circuits. Nat Med 5:888-894. CrossRef Medline

Chen Y, Bender RA, Brunson KL, Pomper JK, Grigoriadis DE, Wurst W, Baram TZ (2004) Modulation of dendritic differentiation by corticotropinreleasing factor in the developing hippocampus. Proc Natl Acad Sci U S A 101:15782-15787. CrossRef Medline 
Chong J, Hesdorffer DC, Thurman DJ, Lopez D, Harris RB, Hauser WA, Labiner ET, Velarde A, Labiner DM (2013) The prevalence of epilepsy along the Arizona-Mexico border. Epilepsy Res 105:206-215. CrossRef Medline

Choy M, Cheung KK, Thomas DL, Gadian DG, Lythgoe MF, Scott RC (2010) Quantitative MRI predicts status epilepticus-induced hippocampal injury in the lithium-pilocarpine rat model. Epilepsy Res 88:221-230. CrossRef Medline

Clarke DD and Sokoloff L (1999) Regulation of cerebral metabolic rate. In: Basic neurochemistry: molecular, cellular and medical aspects, Ed 6 (Siegel GJ, Agranoff BW, Albers RW, Fisher SK, Uhler MD, eds.), pp 637-670. Philadelphia: Lippinott-Raven.

de Graaf RA, Brown PB, McIntyre S, Nixon TW, Behar KL, Rothman DL (2006) High magnetic field water and metabolite proton T1 and T2 relaxation in rat brain in vivo. Magn Reson Med 56:386-394. CrossRef Medline

DeSalvo MN, Schridde U, Mishra AM, Motelow JE, Purcaro MJ, Danielson N, Bai X, Hyder F, Blumenfeld H (2010) Focal BOLD fMRI changes in bicuculline-induced tonic-clonic seizures in the rat. Neuroimage 50:902909. CrossRef Medline

Ding XQ, Kucinski T, Wittkugel O, Goebell E, Grzyska U, Görg M, Kohlschütter A, Zeumer H (2004) Normal brain maturation characterized with age-related $\mathrm{T} 2$ relaxation times: an attempt to develop a quantitative imaging measure for clinical use. Invest Radiol 39:740-746. CrossRef Medline

Dinstein I, Heeger DJ, Lorenzi L, Minshew NJ, Malach R, Behrmann M (2012) Unreliable evoked responses in autism. Neuron 75:981-991. CrossRef Medline

Dosenbach NU, Nardos B, Cohen AL, Fair DA, Power JD, Church JA, Nelson SM, Wig GS, Vogel AC, Lessov-Schlaggar CN, Barnes KA, Dubis JW, Feczko E, Coalson RS, Pruett JR Jr, Barch DM, Petersen SE, Schlaggar BL (2010) Prediction of individual brain maturity using fMRI. Science 329: 1358-1361. CrossRef Medline

Dreifuss S, Vingerhoets FJ, Lazeyras F, Andino SG, Spinelli L, Delavelle J, Seeck M (2001) Volumetric measurements of subcortical nuclei in patients with temporal lobe epilepsy. Neurology 57:1636-1641. CrossRef Medline

Dubé CM, Zhou JL, Hamamura M, Zhao Q, Ring A, Abrahams J, McIntyre K, Nalcioglu O, Shatskih T, Baram TZ, Holmes GL (2009) Cognitive dysfunction after experimental febrile seizures. Exp Neurol 215:167-177. CrossRef Medline

Dubé CM, Ravizza T, Hamamura M, Zha Q, Keebaugh A, Fok K, Andres AL, Nalcioglu O, Obenaus A, Vezzani A, Baram TZ (2010) Epileptogenesis provoked by prolonged experimental febrile seizures: mechanisms and biomarkers. J Neurosci 30:7484-7494. CrossRef Medline

Dubé C, Yu H, Nalcioglu O, Baram TZ (2004) Serial MRI after experimental febrile seizures: altered T2 signal without neuronal death. Ann Neurol 56:709-714. CrossRef Medline

Dubé C, Vezzani A, Behrens M, Bartfai T, Baram TZ (2005a) Interleukin1 beta contributes to the generation of experimental febrile seizures. Ann Neurol 57:152-155. CrossRef Medline

Dubé C, Brunson KL, Eghbal-Ahmadi M, Gonzalez-Vega R, Baram TZ (2005b) Endogenous neuropeptide Y prevents recurrence of experimental febrile seizures by increasing seizure threshold. J Mol Neurosci 25:275284. CrossRef Medline

Dubé C, Richichi C, Bender RA, Chung G, Litt B, Baram TZ (2006) Temporal lobe epilepsy after experimental prolonged febrile seizures: prospective analysis. Brain 129:911-922. CrossRef Medline

Duffy BA, Choy M, Riegler J, Wells JA, Anthony DC, Scott RC, Lythgoe MF (2012) Imaging seizure-induced inflammation using an antibody targeted iron oxide contrast agent. Neuroimage 60:1149-1155. CrossRef Medline

Dunleavy M, Shinoda S, Schindler C, Ewart C, Dolan R, Gobbo OL, Kerskens CM, Henshall DC (2010) Experimental neonatal status epilepticus and the development of temporal lobe epilepsy with unilateral hippocampal sclerosis. Am J Pathol 176:330-342. CrossRef Medline

Englot DJ, Modi B, Mishra AM, DeSalvo M, Hyder F, Blumenfeld H (2009) Cortical deactivation induced by subcortical network dysfunction in limbic seizures. J Neurosci 29:13006-13018. CrossRef Medline

Folbergrová J, Ingvar M, Nevander G, Siesjö BK (1985) Cerebral metabolic changes during and following fluorothyl-induced seizures in ventilated rats. J Neurochem 44:1419-1426. CrossRef Medline
French JA, Williamson PD, Thadani VM, Darcey TM, Mattson RH, Spencer SS, Spencer DD (1993) Characteristics of medial temporal lobe epilepsy: I. Results of history and physical examination. Ann Neurol 34:774-780. CrossRef Medline

Fujikawa DG, Dwyer BE, Wasterlain CG (1986) Preferential blood flow to brainstem during generalized seizures in the newborn marmoset monkey. Brain Res 397:61-72. CrossRef Medline

Gloor P, Olivier A, Quesney LF, Andermann F, Horowitz S (1982) The role of the limbic system in experiential phenomena of temporal lobe epilepsy. Ann Neurol 12:129-144. CrossRef Medline

Goddard GV, McIntyre DC, Leech CK (1969) A permanent change in brain function resulting from daily electrical stimulation. Exp Neurol 25:295330. CrossRef Medline

Goense J, Merkle H, Logothetis NK (2012) High-resolution fMRI reveals laminar differences in neurovascular coupling between positive and negative BOLD responses. Neuron 76:629-639. CrossRef Medline

Greene ND, Bamidele A, Choy M, de Castro SC, Wait R, Leung KY, Begum S, Gadian DG, Scott RC, Lythgoe MF (2007) Proteome changes associated with hippocampal MRI abnormalities in the lithium pilocarpine-induced model of convulsive status epilepticus. Proteomics 7:1336-1344. CrossRef Medline

Gröhn O, Pitkänen A (2007) Magnetic resonance imaging in animal models of epilepsy-noninvasive detection of structural alterations. Epilepsia 48: 3-10. CrossRef Medline

Hascoet JM, Monin P, Vert P (1988) Persistence of impaired autoregulation of cerebral blood flow in the postictal period in piglets. Epilepsia 29:743747. Medline

Hesdorffer DC, Logroscino G, Cascino GD, Hauser WA (2007) Recurrence of afebrile status epilepticus in a population-based study in Rochester, Minnesota. Neurology 69:73-78. CrossRef Medline

Holmes GL, Thompson JL (1988) Effects of kainic acid on seizure susceptibility in the developing brain. Brain Res 467:51-59. Medline

Ivy AS, Rex CS, Chen Y, Dubé C, Maras PM, Grigoriadis DE, Gall CM, Lynch G, Baram TZ (2010) Hippocampal dysfunction and cognitive impairments provoked by chronic early-life stress involve excessive activation of CRH receptors. J Neurosci 30:13005-13015. CrossRef Medline

Jansen JF, Lemmens EM, Strijkers GJ, Prompers JJ, Schijns OE, Kooi ME, Beuls EA, Nicolay K, Backes WH, Hoogland G (2008) Short- and longterm limbic abnormalities after experimental febrile seizures. Neurobiol Dis 32:293-301. CrossRef Medline

Jensen FE, Applegate CD, Holtzman D, Belin TR, Burchfiel JL (1991) Epileptogenic effect of hypoxia in the immature rodent brain. Ann Neurol 29:629-637. CrossRef Medline

Jupp B, Williams JP, Tesiram YA, Vosmansky M, O’Brien TJ (2006) Hippocampal T2 signal change during amygdala kindling epileptogenesis. Epilepsia 47:41-46. CrossRef Medline

Kelley MS, Jacobs MP, Lowenstein DH; NINDS Epilepsy Benchmark Stewards (2009) The NINDS epilepsy research benchmarks. Epilepsia 50: 579-582. CrossRef Medline

Kovac S, Domijan AM, Walker MC, Abramov AY (2012) Prolonged seizure activity impairs mitochondrial bioenergetics and induces cell death. J Cell Sci 125:1796-1806. CrossRef Medline

Koyama R, Tao K, Sasaki T, Ichikawa J, Miyamoto D, Muramatsu R, Matsuki N, Ikegaya Y (2012) GABAergic excitation after febrile seizures induces ectopic granule cells and adult epilepsy. Nat Med 18:1271-1278. CrossRef Medline

Kubová H, Druga R, Lukasiuk K, Suchomelová L, Haugvicová R, Jirmanová I, Pitkänen A (2001) Status epilepticus causes necrotic damage in the mediodorsal nucleus of the thalamus in immature rats. J Neurosci 21:35933599. Medline

Lee CL, Hannay J, Hrachovy R, Rashid S, Antalffy B, Swann JW (2001) Spatial learning deficits without hippocampal neuronal loss in a model of early-onset epilepsy. Neuroscience 107:71-84. CrossRef Medline

Leppert IR, Almli CR, McKinstry RC, Mulkern RV, Pierpaoli C, Rivkin MJ, Pike GB; Brain Development Cooperative Group (2009) T2 relaxometry of normal pediatric brain development. J Magn Reson Imaging 29: 258-267. CrossRef Medline

Lewis DV, Shinnar S, Hesdorffer DC, Bagiella E, Bello JA, Chan S, Xu Y, MacFall J, Gomes WA, Moshé SL, Mathern GW, Pellock JM, Nordli DR Jr, Frank LM, Provenzale J, Shinnar RC, Epstein LG, Masur D, Litherland C, Sun S; FEBSTAT Study Team (2014) Hippocampal sclerosis after fe- 
brile status epilepticus: the FEBSTAT study. Ann Neurol 75:178-185. CrossRef Medline

Lindsay J, Ounsted C, Richards P (1979) Long-term outcome in children with temporal lobe seizures. I: Social outcome and childhood factors. Dev Med Child Neurol 21:285-298. Medline

Lothman E (1990) The biochemical basis and pathophysiology of status epilepticus. Neurology 40:13-23. Medline

Maroso M, Balosso S, Ravizza T, Liu J, Aronica E, Iyer AM, Rossetti C, Molteni M, Casalgrandi M, Manfredi AA, Bianchi ME, Vezzani A (2010) Toll-like receptor 4 and high-mobility group box-1 are involved in ictogenesis and can be targeted to reduce seizures. Nat Med 16:413-419. CrossRef Medline

Mathern GW, Pretorius JK, Babb TL (1995) Influence of the type of initial precipitating injury and at what age it occurs on course and outcome in patients with temporal lobe seizures. J Neurosurg 82:220-227. CrossRef Medline

Mirsattari SM, Sharpe MD, Young GB (2004) Treatment of refractory status epilepticus with inhalational anesthetic agents isoflurane and desflurane. Arch Neurol 61:1254-1259. CrossRef Medline

Natsume J, Bernasconi N, Miyauchi M, Naiki M, Yokotsuka T, Sofue A, Bernasconi A (2007) Hippocampal volumes and diffusion-weighted image findings in children with prolonged febrile seizures. Acta Neurol Scand Suppl 186:25-28. Medline

Nitecka L, Tremblay E, Charton G, Bouillot JP, Berger ML, Ben-Ari Y (1984) Maturation of kainic acid seizure-brain damage syndrome in the rat. II. Histopathological sequelae. Neuroscience 13:1073-1094. CrossRef Medline

Ogawa S, Lee TM, Kay AR, Tank DW (1990) Brain magnetic resonance imaging with contrast dependent on blood oxygenation. Proc Natl Acad Sci U S A 87:9868-9872. CrossRef Medline

Oishi K, Faria AV, Yoshida S, Chang L, Mori S (2013) Quantitative evaluation of brain development using anatomical MRI and diffusion tensor imaging. Int J Dev Neurosci 31:512-524. CrossRef Medline

Olafsson E, Ludvigsson P, Gudmundsson G, Hesdorffer D, Kjartansson O, Hauser WA (2005) Incidence of unprovoked seizures and epilepsy in Iceland and assessment of the epilepsy syndrome classification: a prospective study. Lancet Neurol 4:627-634. CrossRef Medline

Pereira de Vasconcelos A, Ferrandon A, Nehlig A (2002) Local cerebral blood flow during lithium-pilocarpine seizures in the developing and adult rat: role of coupling between blood flow and metabolism in the genesis of neuronal damage. J Cereb Blood Flow Metab 22:196-205. CrossRef Medline

Racine RJ (1972) Modification of seizure activity by electrical stimulation. II. Motor seizure. Electroencephalogr Clin Neurophysiol 32:281-294. CrossRef Medline

Raol YS, Budreck EC, Brooks-Kayal AR (2003) Epilepsy after early-life seizures can be independent of hippocampal injury. Ann Neurol 53:503511. CrossRef Medline
Roch C, Leroy C, Nehlig A, Namer IJ (2002) Predictive value of cortical injury for the development of temporal lobe epilepsy in 21-day-old rats: an MRI approach using the lithium-pilocarpine model. Epilepsia 43: 1129-1136. CrossRef Medline

Scantlebury MH, Gibbs SA, Foadjo B, Lema P, Psarropoulou C, Carmant L (2005) Febrile seizures in the predisposed brain: a new model of temporal lobe epilepsy. Ann Neurol 58:41-49. CrossRef Medline

Schridde U, Khubchandani M, Motelow JE, Sanganahalli BG, Hyder F, Blumenfeld H (2008) Negative BOLD with large increases in neuronal activity. Cereb Cortex 18:1814-1827. CrossRef Medline

Scott RC, Gadian DG, King MD, Chong WK, Cox TC, Neville BG, Connelly A (2002) Magnetic resonance imaging findings within 5 days of status epilepticus in childhood. Brain 125:1951-1959. CrossRef Medline

Shinnar S, Bello JA, Chan S, Hesdorffer DC, Lewis DV, Macfall J, Pellock JM, Nordli DR, Frank LM, Moshe SL, Gomes W, Shinnar RC, Sun S; FEBSTAT Study Team (2012) MRI abnormalities following febrile status epilepticus in children: the FEBSTAT study. Neurology 79:871-877. CrossRef Medline

Sperber EF, Stanton PK, Haas K, Ackermann RF, Moshé SL (1992) Developmental differences in the neurobiology of epileptic brain damage. Epilepsy Res Suppl 9:67-80; discussion 80-81. Medline

Stafstrom CE, Thompson JL, Holmes GL (1992) Kainic acid seizures in the developing brain: status epilepticus and spontaneous recurrent seizures. Brain Res Dev Brain Res 65:227-236. CrossRef Medline

Toth Z, Yan XX, Haftoglou S, Ribak CE, Baram TZ (1998) Seizure-induced neuronal injury: vulnerability to febrile seizures in an immature rat model. J Neurosci 18:4285-4294. Medline

Tremblay E, Ben-Ari Y (1984) Usefulness of parenteral kainic acid as a model of temporal lobe epilepsy. Rev Electroencephalogr Neurophysiol Clin 14:241-246. CrossRef Medline

van Zijl PC, Eleff SM, Ulatowski JA, Oja JM, Uluğ AM, Traystman RJ, Kauppinen RA (1998) Quantitative assessment of blood flow, blood volume and blood oxygenation effects in functional magnetic resonance imaging. Nat Med 4:159-167. CrossRef Medline

VanLandingham KE, Heinz ER, Cavazos JE, Lewis DV (1998) Magnetic resonance imaging evidence of hippocampal injury after prolonged focal febrile convulsions. Ann Neurol 43:413-426. CrossRef Medline

Varghese GI, Purcaro MJ, Motelow JE, Enev M, McNally KA, Levin AR, Hirsch LJ, Tikofsky R, Paige AL, Zubal IG, Spencer SS, Blumenfeld H (2009) Clinical use of ictal SPECT in secondarily generalized tonic-clonic seizures. Brain 132:2102-2113. CrossRef Medline

Vezzani A, French J, Bartfai T, Baram TZ (2011) The role of inflammation in epilepsy. Nat Rev Neurol 7:31-40. CrossRef Medline

Wasterlain CG, Thompson KW, Suchomelova L, Niquet J (2010) Brain energy metabolism during experimental neonatal seizures. Neurochem Res 35:2193-2198. CrossRef Medline

Young RS, Cowan B, Briggs RW (1987) Brain metabolism after electroshock seizure in the neonatal dog: A [31p]NMR study. Brain Res Bull 18:261263. Medline 